\title{
Transcriptome characterization of human mammary cell lines expressing different levels of $E R B B 2$ by serial analysis of gene expression
}

\author{
MARIANA LOPES DOS SANTOS ${ }^{1}$, CAROLINA GONÇALVES PALANCH ${ }^{1}$, SIBELI SALAORNI ${ }^{1}$, \\ WILSON ARAUJO DA SILVA $\mathrm{Jr}^{2}$ and MARIA APARECIDA NAGAI ${ }^{1}$
}

\begin{abstract}
${ }^{1}$ Disciplina de Oncologia, Departamento de Radiologia da Faculdade de Medicina da Universidade de São Paulo, São Paulo; ${ }^{2}$ Departamento de Genética, Faculdade de Medicina de Ribeirão Preto-USP, Ribeirão Preto, Brazil
\end{abstract}

Received October 31, 2005; Accepted December 27, 2005

\begin{abstract}
Over-expression of $E R B B 2$, a member of the family of transmembrane receptor tyrosine kinases, occurs in $15-30 \%$ of primary breast tumors and is associated with poor prognosis and chemoresistance to a variety of anticancer drugs. In this study, aiming to identify differentially-expressed genes involved in erbB2-mediated transformation of the breast, we generated SAGE libraries from two human mammary cell lines, derived from normal luminal cells, expressing different levels of erbB2. The parental cell line HB4a expresses basal levels and the C5.2 expresses high levels of erbB2. A total of 161,632 tags was generated by sequencing, 81,684 from HB4a cells (30,854 unique tags) and 79,948 from C5.2 cells (30,568 unique tags). The comparison between the HB4a and C5.2 libraries revealed 334 distinct transcripts more expressed in HB4a cells and 328 distinct transcripts more expressed in C5.2 cells. The expression pattern of some of these transcripts was further validated by RT-PCR. The C5.2 cell line, which overexpress $E R B B 2$, showed in comparison to HB4a cells a higher percentage of genes involved in transport, RNA processing, apoptosis and protein folding. A higher percentage of the genes more expressed in HB4a cells compared to C5.2 were found to be involved in signal transduction and cytoskeleton organization. The use of SAGE analysis allowed us to identify a significant number of genes implicated in different cellular pathways up- or down-regulated in the presence of ERBB2 over-expression, including genes not previously implicated in breast cancer that could be considered as potential candidate markers for prognosis and therapy.
\end{abstract}

Correspondence to: Dr Maria Aparecida Nagai, Disciplina de Oncologia, Departamento de Radiologia da Faculdade de Medicina da Universidade de São Paulo, Av. Dr Arnaldo 455, $4^{\circ}$ andar, CEP 01246-903, São Paulo, Brazil

E-mail: nagai@usp.br

Key words: breast cancer, SAGE, ERBB2, gene expression

\section{Introduction}

The ERBB2 gene, also known as HER2/NEU, encodes a $185-\mathrm{kDa}$ transmembrane glycoprotein with intrinsic tyrosine kinase activity that belongs to the epidermal growth factor receptor (EGFR) family (1). This family of receptor tyrosine kinases (RTKs) comprises four members, EGFR (ERBB1), $E R B B 2$ (HER2), ERBB3 and ERBB4 that play important roles in several signal transduction pathways regulating cell proliferation, differentiation, cytoskeletal rearrangement and survival $(1,2)$. The RTKs are cell surface allosteric enzymes activated by the ligand-binding that induces receptor monomers to form homo- or heterodimers. Receptor dimerization induces autophosphorylation on tyrosine residues creating binding sites for several adaptor proteins and enzymes, such as Grb2 and Shc, leading to the activation of intracellular signal transduction that includes Ras/Raf/mitogen-activated protein kinase (MAPK) and phosphatidylinositol-3 kinase (PI-3K) pathways $(3,4)$. Although no specific ligand for ERBB2 has been identified it is believed to play a key role in the EGFR family signaling since $E R B B 2$ is the preferred and more effective heterodimerization partner for all other family members $(5,6)$.

Clinical and experimental evidence indicates that ERBB2 over-expression plays important role in the malignant transformation, tumorigenesis and metastasis, however the mechanisms or ERBB2 target genes involved are not fully known. In breast cancer, $E R B B 2$ over-expression usually due to gene amplification has been shown to occur in $15-30 \%$ of invasive ductal tumors, where it correlates with patient poor prognosis and resistance to hormone- and chemotherapy $(7,8)$. Induced over-expression of ERBB2 increases tumorigenic and metastatic potential of breast cancer cells and transgenic mice that over-express $E R B B 2$ display high incidence of mammary tumors and metastasis $(9,10)$. Both in vitro and in vivo experimental results demonstrated that tyrosine kinase inhibitors, anti-sense oligonucleotides, monoclonal antibodies and siRNA are able to abolish the effects of ERBB2 gene in mammary tumorigenesis $(11,12)$. Therefore, ERBB2 also proved to be an excellent target for therapeutic approaches. One example is the humanized antibody for erbB2 called Herceptin, approved for clinical application, has been successfully used for the treatment of breast cancer patients, 
both alone or in combination with other chemotherapeutic regimens $(13,14)$.

Up-regulation of cyclin D1 and down-regulation of p27 $7^{\text {kip } 1}$ has been shown to be associated with cell proliferation and survival during ERBB2 malignant transformation $(15,16)$. Mammary tumors from transgenic mice that over-express $E R B B 2$ under the control of the endogenous promoter show up-regulation of several transcriptional factors associated with the differentiation status of the tumors (17). In fact, gene expression changes in response to ERBB2 over-expression may have a significant impact on several biological processes, such as proliferation, differentiation, cell adhesion, apoptosis and angiogenesis.

The identification of $E R B B 2$ target genes could provide additional insights into the malignant transformation and contribute to improve diagnosis, prognosis and treatment of breast cancer. Differential cDNA hybridization and cDNA microarray techniques have been successfully used to identify differentially-expressed genes in breast cancer cells and tumors (18-22). In the present study, aiming to identify additional $E R B B 2$ target genes, we generated SAGE libraries from two human mammary cell lines, HB4 and C5.2, expressing different levels of ERBB2 (23). Consistent with the role played by $E R B B 2$ signaling in behavior of mammary epithelial cells and tumors, using this approach we were able to identify potential ERBB2 target genes implicated in a variety of cellular processes including cell proliferation, apoptosis and cytoskeleton organization.

\section{Materials and methods}

Cell culture. The mammary cell lines HB4a, C3.6 and C5.2 were kindly provided by Dr Michael O'Hare from Ludwig Institute for Cancer Research, London, UK. The parental HB4a is a normal mammary luminal epithelial cell line established as previously described (24). C3.6 and C5.2 cell lines were obtained by the transfection of HB4a cells with full-length normal human ERBB2 cDNA derived from the breast cancer cell line BT474 (23). These cells were cultured in RPMI-1640 supplemented with $10 \%$ FCS, $2 \mathrm{mM}$ glutamine, $100 \mathrm{IU} / \mathrm{ml}$ penicillin, $100 \mu \mathrm{g} / \mathrm{ml}$ streptomycin and $5 \mu \mathrm{g} / \mathrm{ml}$ hydrocortisone and insulin in a $5 \% \mathrm{CO}_{2}$ humidifier incubator at $37^{\circ} \mathrm{C}$.

RNA extraction. For total RNA extraction the cells were washed twice with PBS, harvested and homogenized in a solution containing guanidine isothiocyanate (4 M guanidine isothiocyanate, $25 \mathrm{mM}$ sodium citrate $\mathrm{pH} 7.0,0.5 \%$ sarcosyl and $100 \mathrm{mM}$ ß-mercaptoethanol) and extracted as described (25). The quality of the RNA samples was determined by $1 \%$ agarose gel electrophoresis and ethidium bromide staining. All RNA samples were treated with DNase I for $1 \mathrm{~h}$ at $37^{\circ} \mathrm{C}$ to eliminate genomic DNA contamination.

Serial analysis of gene expression (SAGE). Total RNA (25 $\mu \mathrm{g})$ isolated from HB4a and C5.2 cell lines were used to generate SAGE libraries. SAGE was carried out using the I-SAGE kit (Invitrogen) according to the manufacturer's protocol based on the original SAGE method (26). Concatemerized ditags were cloned into pZERO-1 and the amplified inserts were sequenced using ET Dye Terminator Kit (Amersham Bio-
Table I. Summary of SAGE analysis in human mammary luminal cells HB4a and C5.2.

\begin{tabular}{lrr}
\hline & HB4a & C5.2 \\
\hline Total no. of tags & 81,684 & 79,948 \\
Unique tags & 30,854 & 30,568 \\
Annotated tags & 19,314 & 19,181 \\
Tag-gene & 7,698 & 7,616 \\
\hline
\end{tabular}

sciences) and forward M13 primer and analyzed with a Mega BACE 1000 automated sequencer (Amersham Biosciences). Tag frequency tables were obtained from sequences by $\mathrm{SAGE}^{\mathrm{TM}}$ analysis software, with minimum tag count set to one, maximum ditag length set to 28 , and other parameters set as default. The annotation was based on two specific tools, SAGEmap (http://www.ncbi.nlm.nih.gov/SAGE) and CGAP SAGE Genie (http://cgap.ncbi.nih.gov/SAGE).

Semi-quantitative RT-PCR. Total RNA $(10 \mu \mathrm{g})$ was reversetranscribed using the High Capacity cDNA Archive kit (Applied Biosystems). PCR amplification was performed in $25 \mu 1$ volume using $50 \mathrm{ng}$ of $\mathrm{cDNA}, 0.6 \mu \mathrm{M}$ of each primer, $1.5 \mathrm{mM} \mathrm{MgCl}_{2}, 125 \mu \mathrm{M}$ of each deoxynucleotide triphosphate, $50 \mathrm{mM} \mathrm{KCl}, 10 \mathrm{mM}$ Tris- $\mathrm{HCl} \mathrm{pH} \mathrm{8.0,} \mathrm{and} 0.2$ unit of Taq DNA polymerase (Invitrogen, Carlsbad, USA) and consisted of 28 and 32 cycles of denaturation for $30 \mathrm{sec}$ at $94^{\circ} \mathrm{C}$, annealing for $1 \mathrm{~min}$ at $55^{\circ} \mathrm{C}$ and extension for $1 \mathrm{~min}$ at $72^{\circ} \mathrm{C}$, followed an extension of $5 \mathrm{~min}$ at $72^{\circ} \mathrm{C}$. The expression of glyceraldehyde-3-phosphate dehydrogenase $(G A P D)$ gene was used as an internal control for cDNA input. The PCR products were separated by electrophoresis on $2 \%$ agarose gels stained by ethidium bromide.

\section{Results}

Aiming to identify genes involved in erbB2-mediated transformation of the breast we compared the gene expression profiles of two human mammary luminal epithelial cell lines expressing different levels of erbB2 using SAGE technique. Two independent SAGE libraries were constructed from HB4a (the parental cell line showing basal expression levels of erbB2) and C5.2 (showing high expression of erbB2) cell lines.

A total of 161,632 tags was generated by sequencing, 81,684 tags derived from HB4a and 79,948 derived from C5.2 cell lines (Table I). Excluding redundancy the sequence analysis identified 30,854 and 30,568 distinct tags from HB4a and C5.2 cells, respectively. In HB4a SAGE library, 19,314 from 30,854 unique tags correspond to UniGene clusters representing known genes, hypothetical proteins and expressed sequence tags (ESTs), the remaining 11,540 tags showed no matches in the CGAP SAGE Genie. In HB4a SAGE library, 19,181 from 30,568 unique tags correspond to UniGene clusters representing known genes, hypothetical proteins and expressed sequence tags (ESTs), the remaining 11,387 tags showed no matches in the CGAP SAGE Genie.

The comparison between the two SAGE libraries was performed using the tools found in our website (http://gdm. 
Table II. List of the top 50 genes up-regulated in HB4a vs. C5.2 mammary cells.

\begin{tabular}{|c|c|c|c|c|c|}
\hline TAG & UniGene & Description (locus name) & HB4a & C5.2 & $\begin{array}{l}\text { Chromosome } \\
\text { localization }\end{array}$ \\
\hline AAAATATTTT & Hs. 509765 & Actinin, alpha 1 (ACTN1) & 23.00 & 1.02 & $14 \mathrm{q} 24.1-\mathrm{q} 24.2$ \\
\hline AAAGCCAAGA & Hs.74047 & Electron-transfer-flavoprotein, beta polypeptide (ETFB) & 18.00 & 0.00 & $19 q 13.3$ \\
\hline AAGTGAGATG & Hs. 272822 & RuvB-like 1 (E. coli) (RUVBL1) & 15.00 & 0.00 & $3 q 21$ \\
\hline AAGAGTTACG & Hs.55041 & Mitochondrial ribosomal protein L2 (MRPL2) & 15.00 & 1.02 & $6 \mathrm{p} 21.3$ \\
\hline AGAAATGTAT & Hs. 282113 & SNF1-like kinase (SNF1LK) & 14.00 & 1.02 & $21 \mathrm{q} 22.3$ \\
\hline AGTGTGATAC & Hs. 118820 & Hypothetical protein BC007882 (LOC152217) & 14.00 & 1.02 & $3 q 29$ \\
\hline AGGAAAAGAT & Hs. 523829 & Polymerase (DNA-directed), delta 4 (POLD4) & 12.00 & 1.02 & $11 \mathrm{q} 13$ \\
\hline CTTGACATAC & Hs. 171695 & Dual specificity phosphatase 1 (DUSP1) & 12.00 & 1.02 & $5 q 34$ \\
\hline AGGGCTACGG & BF571807 & EST & 12.00 & 1.02 & \\
\hline CCAGCCCAGC & Hs.29802 & Slit homolog 2 (Drosophila) (SLIT2) & 11.00 & 1.02 & $4 \mathrm{p} 15.2$ \\
\hline ACTGCGAGGA & Hs.110477 & Dolichyl-phosphate mannosyltransferase polypeptide 3 (DPM3) & 10.00 & 0.00 & $1 \mathrm{q} 22$ \\
\hline ATGTCTTTTC & Hs.462998 & Insulin-like growth factor binding protein 4 (IGFBP4) & 10.00 & 1.02 & $17 q 12-q 21.1$ \\
\hline GGCCTTTTTT & Hs.75307 & H1 histone family, member X (H1FX) & 10.00 & 1.02 & $3 \mathrm{q} 21.3$ \\
\hline CTACGTGCTC & Hs. 521056 & ATP synthase, mitochondrial F0 complex, sub f, isoform 2 (ATP5J2) & 9.00 & 1.02 & $7 \mathrm{q} 22.1$ \\
\hline AATTTGCAAC & Hs.420272 & H2A histone family, member Y (H2AFY) & 9.00 & 1.02 & $5 q 31.3-q 32$ \\
\hline CTTGATTCCC & Hs. 518374 & Quiescin Q6 (QSCN6) & 9.00 & 1.02 & $1 \mathrm{q} 24$ \\
\hline CACTTGAAAA & Hs. 7753 & Calumenin (CALU) & 9.00 & 1.02 & $7 \mathrm{q} 32$ \\
\hline TTGGGAGCAG & Hs.445403 & Isoleucine-tRNA synthetase (IARS) & 9.00 & 1.02 & $9 \mathrm{q} 21$ \\
\hline ACGATTGATG & Hs. 528320 & Apolipoprotein A-I binding protein (APOA1BP) & 9.00 & 1.02 & $1 \mathrm{q} 22$ \\
\hline AAAATAAAAA & Hs. 517373 & Protoporphyrinogen oxidase (PPOX) & 9.00 & 1.02 & $1 \mathrm{q} 22$ \\
\hline CGTTCCTGCG & Hs.504609 & $\begin{array}{l}\text { Inhibitor of DNA binding 1, dominant negative helix-loop-helix } \\
\text { protein (ID1) }\end{array}$ & 9.00 & 1.02 & $20 \mathrm{q} 11$ \\
\hline ATGTGAAGAG & Hs.111779 & Secreted protein, acidic, cysteine-rich (osteonectin) (SPARC) & 141.00 & 17.34 & $5 \mathrm{q} 31.3-\mathrm{q} 32$ \\
\hline GATCCCAAAC & BF686592 & EST & 8.00 & 0.00 & \\
\hline TTCTTGCTTA & Hs. 425777 & Ubiquitin-conjugating enzyme E2L 6 (UBE2L6) & 8.00 & 0.00 & $11 \mathrm{q} 12$ \\
\hline AAGAAAACTG & Hs.352671 & Crystallin, zeta (quinone reductase)-like 1 (CRYZL1) & 8.00 & 0.00 & $21 \mathrm{q} 21.3$ \\
\hline CTTGGTTCTC & Hs. 501578 & Shadow of prion protein (Sprn) & 8.00 & 0.00 & $10 q 26.3$ \\
\hline AATACCTCGT & Hs.414579 & Scotin (SCOTIN) & 8.00 & 0.00 & $3 \mathrm{p} 21.31$ \\
\hline GTTGCTGCCC & Hs.9234 & Seven transmembrane domain protein (NIFIE14) & 8.00 & 0.00 & $19 \mathrm{q} 13.1$ \\
\hline TTAAAGATTT & Hs.133892 & Tropomyosin 1 (alpha) (TPM1) & 8.00 & 0.00 & $15 \mathrm{q} 22.1$ \\
\hline GCCAAGATGC & Hs.515164 & $\begin{array}{l}\text { Growth arrest and DNA-damage-inducible, gamma interacting } \\
\text { protein } 1 \text { (GADD45GIP1) }\end{array}$ & 16.00 & 2.04 & $19 \mathrm{p} 13.13$ \\
\hline AACATTCTAA & Hs.530436 & Syntaxin binding protein 3 (STXBP3) & 8.00 & 1.02 & $1 \mathrm{p} 13.3$ \\
\hline TATCAATATT & Hs.213424 & Secreted frizzled-related protein 1 (SFRP1) & 8.00 & 1.02 & 8p12-p11.1 \\
\hline AAGGAGTCCC & Hs. 333427 & CD320 antigen (8D6A) & 8.00 & 1.02 & $19 \mathrm{p} 13.3-\mathrm{p} 13.2$ \\
\hline CTCTAGAACC & Hs.292579 & Phosphatidylserine synthase 1 (PTDSS1) & 8.00 & 1.02 & $8 \mathrm{q} 22$ \\
\hline GCATCTGTTT & Hs.520189 & ELOVL family member 5 (ELOVL5) & 8.00 & 1.02 & 6p21.1-p12.1 \\
\hline AACCAGAGGT & T69505 & EST & 8.00 & 1.02 & \\
\hline TAACAAAGAA & Hs. 405537 & $\begin{array}{l}\text { Protein kinase, interferon-inducible double stranded RNA dependent } \\
\text { activator (PRKRA) }\end{array}$ & 8.00 & 1.02 & $2 \mathrm{q} 31.2$ \\
\hline GAATAAAATA & Hs.269592 & Putative NFאB activating protein (FLJ20241) & 8.00 & 1.02 & $19 \mathrm{p} 13.12$ \\
\hline GACTCTTCAG & Hs.534293 & $\begin{array}{l}\text { Serine (or cysteine) proteinase inhibitor, clade A (alpha-1 } \\
\text { antiproteinase, antitrypsin), member } 3 \text { (SERPINA3) }\end{array}$ & 8.00 & 1.02 & $14 q 32.1$ \\
\hline TGATTTATTC & Hs. 465870 & Kelch-like ECH-associated protein 1 (KEAP1) & 8.00 & 1.02 & $19 \mathrm{p} 13.2$ \\
\hline ATGGCAACAG & Hs.505654 & Integrin, alpha 5 (fibronectin receptor, alpha polypeptide) (ITGA5) & 8.00 & 1.02 & $12 q 11-q 13$ \\
\hline TGGCTTAAAT & Hs.521171 & Hypoxia-inducible protein 2 (HIG2) & 8.00 & 1.02 & $7 \mathrm{q} 32.2$ \\
\hline AAAGTGCATC & Hs.193326 & Fibroblast growth factor receptor-like 1 (FGFRL1) & 8.00 & 1.02 & $4 \mathrm{p} 16$ \\
\hline GACCTCCTGC & Hs.502872 & Mitogen-activated protein kinase kinase kinase 11 (MAP3K11) & 8.00 & 1.02 & $11 \mathrm{q} 13.1-\mathrm{q} 13.3$ \\
\hline GATTTCAACC & Hs.371698 & RNA export 1 homolog (S. pombe) (RAE1) & 7.00 & 0.00 & $20 q 13.32$ \\
\hline GTGGGGGGAG & Hs.446374 & HLA class II region expressed gene KE2 (HKE2) & 7.00 & 0.00 & $6 \mathrm{p} 21.3$ \\
\hline AATGACTGAA & Hs.93659 & Protein disulfide isomerase-associated 4 (ERP70) & 7.00 & 0.00 & $7 \mathrm{q} 35$ \\
\hline ATGCGGGAGA & Hs. 534521 & Beta-casein-like protein (BCLP) & 7.00 & 0.00 & $1 \mathrm{p} 35-\mathrm{p} 34$ \\
\hline CACTCTATCC & Hs. 258551 & Aspartyl aminopeptidase (DNPEP) & 7.00 & 0.00 & $2 q 35$ \\
\hline TACAAACCTG & Hs.513626 & Metallothionein 1F (functional) (MT1F) & 7.00 & 0.00 & $16 \mathrm{q} 13$ \\
\hline
\end{tabular}


Table III. List of the top 50 genes up-regulated in C5.2 vs. HB4 mammary cells.

\begin{tabular}{|c|c|c|c|c|c|}
\hline TAG & UniGene & Description (locus name) & $\mathrm{HB} 4 \mathrm{a}$ & C5.2 & $\begin{array}{c}\text { Chromosome } \\
\text { localization }\end{array}$ \\
\hline CTGTGTTTAG & Hs. 452583 & Transcribed locus, strongly similar to NP_061322.2 matrin 3 & 0.00 & 230.52 & $5 q 31.2$ \\
\hline CCAGGAACCT & Hs. 446352 & v-erb-b2 erythroblastic leukemia viral oncogene homolog 2 (ERBB2) & 0.00 & 85.68 & $17 \mathrm{q} 11.2-\mathrm{q} 12$ \\
\hline GCAGGTTCCC & AI624297 & EST & 1.00 & 19.38 & \\
\hline TAAGTAAAGT & Hs.368260 & Hypothetical protein MGC11242 (MGC11242) & 0.00 & 16.32 & $17 q 21.32$ \\
\hline CTATTTAGGG & Hs.7736 & Mitochondrial ribosomal protein L27 (MRPL27) & 0.00 & 16.32 & $17 \mathrm{q} 21.3-\mathrm{q} 22$ \\
\hline ТСТТСТСССТ & Hs. 506748 & Hepatoma-derived growth factor (HDGF) & 1.00 & 14.28 & $1 q 21-q 23$ \\
\hline CCCAGCTAAT & Hs.200395 & Centromere protein $\mathrm{H}(\mathrm{CENPH})$ & 2.00 & 25.50 & $5 \mathrm{p} 15.2$ \\
\hline TGATTGGTGG & Hs.74615 & Platelet-derived growth factor receptor, alpha polypeptide (PDGFRA) & 1.00 & 12.24 & $4 q 11-q 13$ \\
\hline GCCCCCAATA & Hs.445351 & Lectin, galactoside-binding, soluble, 1 (galectin 1) (LGALS1) & 2.00 & 23.46 & $22 \mathrm{q} 13.1$ \\
\hline TACCATCGAT & BI226498 & EST & 1.00 & 11.22 & \\
\hline GGCAGAGACC & Hs. 467133 & Nucleoporin 62 kDa (NUP62) & 1.00 & 11.22 & $19 q 13.33$ \\
\hline GCTCTGCCTC & Hs.252549 & Cathepsin Z (CTSZ) & 0.00 & 10.20 & $20 \mathrm{q} 13$ \\
\hline CACGCAATGC & Hs. 515053 & Amino-terminal enhancer of split (AES) & 1.00 & 10.20 & $19 \mathrm{p} 13.3$ \\
\hline GATTTTGTAG & Hs. 494604 & $\begin{array}{l}\text { Acidic (leucine-rich) nuclear phosphoprotein } 32 \text { family, member B } \\
\text { (ANP32B) }\end{array}$ & 2.00 & 18.36 & $9 \mathrm{q} 22.32$ \\
\hline TAGCTTCCTT & Hs.44276 & Homeo box C10 (HOXC10) & 1.00 & 9.18 & $12 \mathrm{q} 13.3$ \\
\hline TAAACATTGT & Hs. 468140 & DKFZP564F0522 protein (DKFZP564F0522) & 1.00 & 9.18 & $2 \mathrm{p} 22.3$ \\
\hline GTAGACACCT & Hs.418133 & $\begin{array}{l}\text { Intracellular membrane-associated calcium-independent } \\
\text { phospholipase A2 gamma (IPLA2 GAMMA) }\end{array}$ & 2.00 & 17.34 & $7 q 31$ \\
\hline ATGGCAGGAG & Hs.194121 & RNA terminal phosphate cyclase-like 1 (RCL1) & 0.00 & 8.16 & $9 \mathrm{p} 24.1-\mathrm{p} 23$ \\
\hline TAAATACAGT & Hs.503043 & Carnitine palmitoyltransferase 1A (liver) (CPT1A) & 0.00 & 8.16 & $11 \mathrm{q} 13.1-\mathrm{q} 13.2$ \\
\hline TGTATCACTG & BF932124 & EST & 0.00 & 8.16 & \\
\hline CATTGTAATA & BE871060 & EST & 0.00 & 8.16 & \\
\hline CCTAAGGCTA & Hs.108371 & E2F transcription factor 4, p107/p130-binding (E2F4) & 0.00 & 8.16 & $16 \mathrm{q} 21-\mathrm{q} 22$ \\
\hline TGGATCAACC & Hs.74034 & Caveolin 1, caveolae protein, $22 \mathrm{kDa}$ (CAV1) & 0.00 & 8.16 & $7 \mathrm{q} 31.1$ \\
\hline CAGGAACCTG & BE468107 & EST & 0.00 & 8.16 & \\
\hline TCACAGCTGT & Hs.255935 & B-cell translocation gene 1, anti-proliferative (BTG1) & 2.00 & 16.32 & $12 q 22$ \\
\hline CTACCAGGCC & Hs. 334848 & Hypothetical protein FLJ13291 (FLJ13291) & 1.00 & 8.16 & $16 \mathrm{q} 22.1$ \\
\hline TCTCAATTCT & Hs. 467637 & Cell division cycle 42 (GTP binding protein, $25 \mathrm{kDa}$ ) (CDC42) & 1.00 & 8.16 & $1 \mathrm{p} 36.1$ \\
\hline GCTTTCATTG & Hs.2704 & Glutathione peroxidase 2 (GPX2) & 1.00 & 8.16 & $14 \mathrm{q} 24.1$ \\
\hline TTTTGATAAA & Hs.388927 & YY1 transcription factor (YY1) & 1.00 & 8.16 & $14 \mathrm{q}$ \\
\hline TCTGCTAAAG & Hs. 475685 & High-mobility group box 1 (HMGB1) & 1.00 & 8.16 & $13 q 12$ \\
\hline AAGAGTTGGG & Hs. 536652 & Transcribed locus & 1.00 & 8.16 & \\
\hline TAAGCAGATG & Hs.306425 & Inhibitor of Bruton agammaglobulinemia tyrosine kinase (IBTK) & 1.00 & 8.16 & $6 \mathrm{q} 14.1$ \\
\hline GCGAAACCCC & Hs.288945 & Hypothetical protein FLJ13448 (FLJ13448) & 1.00 & 8.16 & $2 q 33.1$ \\
\hline CAGAATAATA & Hs.204475 & HIV TAT specific factor 1 (HTATSF1) & 1.00 & 8.16 & $\mathrm{Xq} 26.1-\mathrm{q} 27.2$ \\
\hline GATTTGTAGC & BE279179 & EST & 2.00 & 15.30 & \\
\hline ACCGCCTGTG & Hs.79625 & Chromosome 20 open reading frame 149 (C20orf149) & 2.00 & 15.30 & $20 q 13.33$ \\
\hline TCCTTTGCAA & Hs.81892 & KIAA0101 (KIAA0101) & 0.00 & 7.14 & $15 q 22.31$ \\
\hline CTACATAATA & Hs.432385 & DEAD (Asp-Glu-Ala-Asp) box polypeptide 7 (DDX7) & 0.00 & 7.14 & 21 \\
\hline CTGCCTCCTT & Hs. 472847 & Chromosome 20 open reading frame 35 (C20orf35) & 0.00 & 7.14 & $20 q 13.12$ \\
\hline GCTACAGGTA & Hs.349306 & Hypothetical protein FLJ31951 (FLJ31951) & 0.00 & 7.14 & $5 \mathrm{q} 33.3$ \\
\hline TTCAAGAAAC & Hs.458974 & Transcribed locus & 0.00 & 7.14 & 8 \\
\hline CTCATAAGAA & Hs. 549495 & Transcribed locus, strongly similar to XP_529639.1 & 0.00 & 7.14 & 14 \\
\hline TTAGCTTGTT & BU074305 & EST & 0.00 & 7.14 & \\
\hline CAGGATCCAG & Hs. 447477 & Family with sequence similarity 10, member A5 (FAM10A5) & 0.00 & 7.14 & $11 \mathrm{p} 15.1$ \\
\hline GCAGATCGGG & BF336989 & EST & 0.00 & 7.14 & \\
\hline GCGGAGAGAG & Hs.546104 & Transcribed locus & 3.00 & 21.42 & $\mathrm{X}$ \\
\hline AGTAGGTGGC & Hs.459311 & Hypothetical protein DKFZp547K1113 (DKFZp547K1113) & 2.00 & 14.28 & $15 \mathrm{q} 26.1$ \\
\hline CGAATAAAAT & Hs.139896 & Macrophage erythroblast attacher (MAEA) & 2.00 & 14.28 & $4 \mathrm{p} 16.3$ \\
\hline TACAATAAAC & Hs.507910 & Progesterone receptor membrane component 2 (PGRMC2) & 1.00 & 7.14 & $4 q 26$ \\
\hline GTTGTGATGT & Hs.374477 & Ewing sarcoma breakpoint region 1 (EWSR1) & 1.00 & 7.14 & $22 \mathrm{q} 12.2$ \\
\hline
\end{tabular}




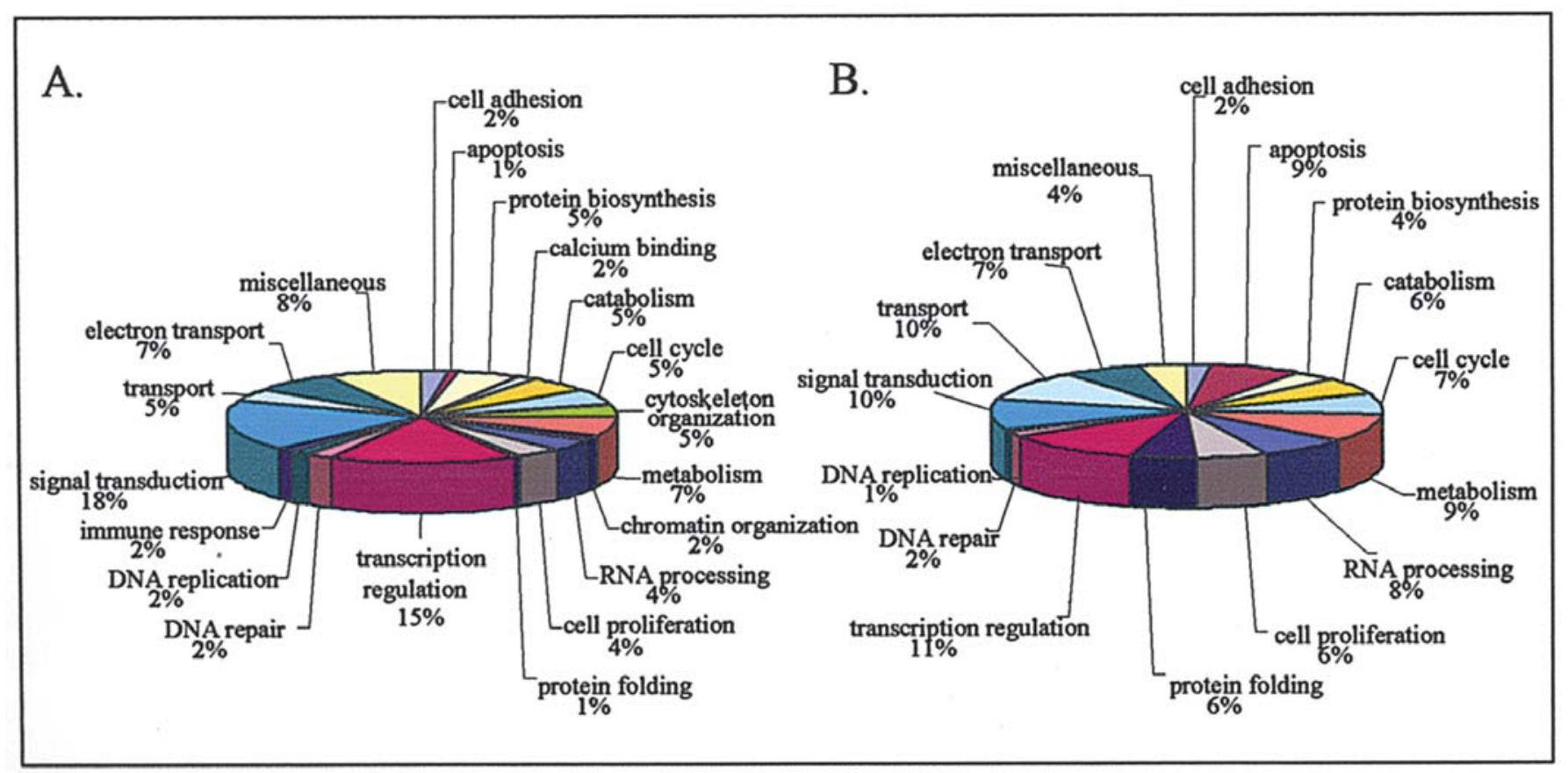

Figure 1. Distribution of the more expressed transcripts from HB4a (A) and C5.2 (B) cell lines classified by functional categories using Gene Ontology nomenclature.

fmrp.usp.br/cgi-bin/gc/uploadFace.pl). Using a cut-off at $\geq 4$-fold changes between the transcripts from HB4a and C5.2 libraries we detected 334 distinct genes more expressed in HB4a and 328 distinct genes more expressed in C5.2. The list of the 50 most expressed genes in the HB4a and C5.2 cells is shown in Tables II and III, respectively. A complete list of the differentially-expressed genes (cut-off $\geq 4$-fold changes) are shown as supplementary Tables II and III). Public available databases (e.g. Gene Ontology, Locus Link, UniGene cluster) were used to annotate by biological function the genes more expressed in each cell line. No functional roles could be assigned for $70(21 \%)$ of the transcripts more expressed in HB4a cells and 95 (29\%) of the transcripts more expressed in C5.2. The majority of the other transcripts could be classified using Gene Ontology nomenclature (Fig. 1). C5.2 cell line, which over-expressed the erbB2 gene, showed in comparison to HB4a cells a higher percentage of genes involved in apoptosis (C5.2, 9\% vs. HB4a, 1\%), transport (C5.2, $10 \%$ vs. HB 4a, 5\%), RNA processing (C5.2, $8 \%$ vs. HB4a, $4 \%$ ) and protein folding (C5.2, 6\% vs. HB4a, 1\%). A higher percentage of the genes more expressed in HB4a cells compared to C5.2 were found to be involved in signal transduction (HB4a, 18\% vs. C5.2, $10 \%$ ) and cytoskeleton organization (HB4a, $5 \%$ vs. C5.2, $0 \%$ ).

Based on tag abundance and functional annotation, 9 of the differentially-expressed genes were selected for validation by RT-PCR. Those included 5 genes up-regulated (MATR3, $M G C 11242, H D G F, C E N P H$ and $A N P 32 B)$ and 4 downregulated (ETFB, RUVBL1, SPARC and SFRPI) in C5.2 as compared to HB4a cells. The cell line C3.6, which shows moderate expression of the erbB2 gene, was also included in the validation analysis. The expression pattern of the 9 genes selected from SAGE technique was confirmed by RT-PCR analysis (Fig. 2).

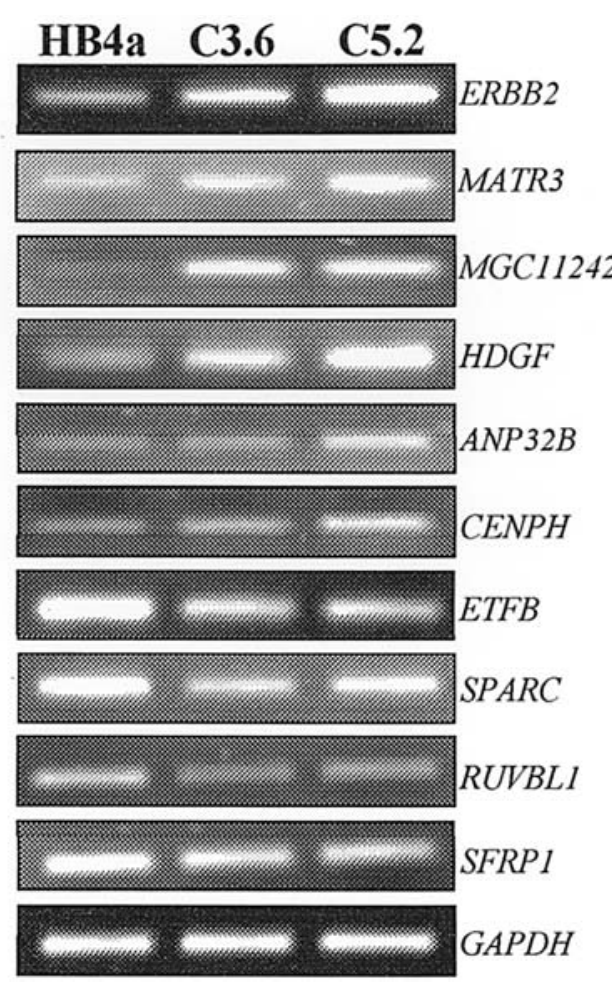

Figure 2. Validation by RT-PCR analysis of 9 differentially-expressed genes from HB4a and C5.2 SAGE libraries.

\section{Discussion}

ERBB2 over-expression activates important cell signaling pathways including ras/raf/MAPK and PI3K/AKT leading to the activation and repression of downstream genes especially involved in cell proliferation and survival implicated in 
malignant transformation. Transgenic mice over-expressing $E R B B 2$ develop mammary tumors with high incidence and $E R B B 2$ over-expression has been demonstrated in $15-30 \%$ of human breast cancer in association with poor prognosis and resistance to hormone- and chemotherapy $(1,27)$. The identification of ERBB2 target genes may provide new insights into the tumorigenic process of the breast that could also have impact on diagnosis, prognosis and treatment of the disease.

In the present study, we used serial analysis of gene expression (SAGE) to characterize the transcriptome of two human mammary epithelial cell lines expressing different levels of $E R B B 2$ and to identify $E R B B 2$ regulated genes. The SAGE technique offers the opportunity of both high-throughput and quantitative analysis of gene expression profiles of a cell or tissue including known as well as unknown genes. The use of SAGE approach has enabled us to confirm previous data reported by others and to extend the number of new candidate genes up- or down-regulated by ERBB2 in human mammary cells. Comparison of our SAGE results with the data reported by Mackay et al (20) in the same cell lines (HB4a and C5.2) but using a cDNA microarray containing 6,000 different transcripts showed many similarities. Not all, but several of the 61 transcripts identified by these authors as up-regulated, such as LGALS1, CRIP1, S100P, MGC11242, SQLIE, HSPB1, DNAJB6 or down-regulated, such as MYL9, SPARC, FN1, TAGLN, SPINT2, GTF3B, PMSD8 in the C5.2 cell line, which expresses high levels of ERBB2, showed the same pattern in our SAGE libraries, indicating that both platforms, cDNA microarrays and SAGE, are very sensitive methods to determine gene expression profiling. However, the use of SAGE technique allowed us to identify a large number of transcripts not previously identified as ERBB2 regulated genes including those with unknown function. The relative abundance of the differentially-expressed transcripts in our SAGE libraries was validated by RT-PCR analysis. All nine genes analyzed by RT-PCR displayed the same expression pattern observed in the SAGE analysis, such as MATR3, MGC11242, HDGF, $A N P 32 B$ and $C E N P H$ found to be up-regulated and $E T F B$, $S P A R C, R U V B L 1$ and $S F R P 1$ found to be down-regulated in cells over-expressing $E R B B 2$. However, the differences in the transcript levels were more evident in SAGE libraries, this lack of complete concordance could be due to the lower sensitivity of semi-quantitative RT-PCR to detect transcript abundance.

The malignant transformation involves changes in cell proliferation and survival, cell shape and cytoskeleton and alterations of cell adhesion. Several lines of evidence have implicated $E R B B 2$ in cell proliferation, differentiation and apoptosis. We further divided the most up-regulated and down-regulated genes into functional categories. Overexpression of $E R B B 2$ affected the expression of genes involved in different biological processes. Interestingly, the C5.2 cell line that over-express $E R B B 2$ showed a higher percentage of genes involved in cell cycle/proliferation, apoptosis and protein folding and lower percentage of genes involved in cytoskeleton organization than HB4a cell line.

A higher number of apoptosis-related genes were observed in the C5.2 library than in the HB4a library. Most of these genes (PBP, PDCD4, ANP32B, BTG1, BNIP1) play proapoptotic activity and show elevated expression probably in response to the oncogenic stress experienced by the C5.2 cells. However, the ability of these genes to sensitize C5.2 cells to apoptose is possible overcome by ERBB2 over-expression that evokes activation of the PI3K and AKT and promotes cellular survival $(28,29)$. Active PBK/AKT has been shown to protect against apoptosis through phosphorylation and inhibition of proapoptotic proteins such as Bad and Foxo (30-32). However, if this is the case, the proapoptotic genes identified here requires further experimental studies.

In our SAGE analysis, several genes encoding for chaperone and co-chaperone proteins such as Hsp90, Hsp70, Hsp40 and Hsp27 were detected as up-regulated in the C5.2 cell line, which over-express $E R B B 2$. Heat shock proteins are an important family of endogenous protective proteins expressed in all tissues and induced under various stresses and different signals (33). Hsp70 and Hsp90 participate in the folding of numerous proteins including oncoproteins and also play critical roles in maintaining the estrogen receptor conformation for proper ligand binding $(34,35)$. High expression of Hsp90, Hsp70 and Hsp27 in human tumors, including breast cancer, is correlated with poor prognosis and therapy resistance (36). Furthermore, those heat shock proteins have anti-apoptotic functions. The chaperone Hsp90 has been shown to stabilize anti-apoptotic proteins such as survivin and RIP and to inhibit pro-apoptotic kinase ASK1 (apoptosis signal regulator kinase 1) (37-39). Moreover, inhibition of Hsp90 by geldanamycin induces growth arrest and apoptosis in cells over-expressing ERBB2 $(40,41)$. Depletion of Hsp70 induces massive cell death in different tumorigenic cell lines revealing its anti-apoptotic function $(42,43)$. There is also evidence showing that Hsp27 display anti-apoptotic activity. Hsp27 expression protects from apoptosis induced by TNF- $\alpha$ and chemically-induced cell death $(44,45)$. Although the differential expression pattern of chaperone protein observed here could reflect the cellular adaptation to several types of stress, these differences may in part account for the increased cell survival and drug resistance associated with ERBB2 over-expression.

Altered cytoskeleton organization is a hallmark of transformed cells, which acquire a more rounded shape and increased cell invasive and metastatic potential. In our SAGE analysis we identified down-regulation of genes associated with cytoskeleton organization such as ACTN1 and TPM1. This finding is consistent with the disorganized and irregular shape displayed by the cell line C5.2 on Matrigel in comparison to the parental cell line HB4a (23). The role played by the ACTN1 in cancer is unclear. The ACTN1 encodes for a member of the $\alpha$-actinin family that bind actin and play a key role in the assembly and maintenance of stress fibers in non-muscle cells $(46,47)$. $\alpha$-actinin 1 is believed to link actin cytoskeleton to adhesion plaques via integrins and other actin-binding proteins (48-50). The expression of $\alpha$-actinin 1 has also been found to be down-regulated in SV40-transformed NIH3T3 cells (51), indicating that loss of $\alpha$-actinin 1 may play a role in malignant transformation. A recent study showed that erbB2 induces integrin inactivation in breast cancer cells through actin cytoskeletal rearrengement dependent on PI3K and PKB pathways (52).

Tropomyosin 1 (TPM1) one of the genes found to be down-regulated in the cell line with ERBB2 over-expression 
is a member of a family of actin binding proteins that play important function in microfilament stabilization $(53,54)$. TPM1 expression is down-regulated in several transformed cells, including breast cancer cells (54-56) and restoration of its expression is able to revert the malignant phenotype of oncogene-transformed cells (57). Primary breast tumors express low or undetectable levels of TPM1 (58). In fact, TPM1 has been shown to suppress the malignant phenotype of breast cancer cells. Restoration of TPM1 expression in $\mathrm{MCF}-7$ cells decreases cell proliferation, inhibits anchorageindependent growth and alters interaction of E-cadherin-catenin complex contributing to the stability of cell-cell adherens junctions (59). Down-regulation of both ACTN1 and TPM1 expression could be a result of the activation of ERBB2 signaling pathways that induces actin reorganization and motility, enhances the invasiveness and metastatic potential and chemoresistance of cancer cells (60).

Using serial analysis of gene expression (SAGE), we identified a large number of differentially-expressed genes in human mammary epithelial cells over-expressing ERBB2 that are associated with different biological processes. Several of these genes are new or hypothetical proteins not previously implicated in breast cancer. Although, further experimental and clinical studies are required, some of these genes could be considered as potential candidate markers of the aggressive phenotype displayed by breast tumors over-expressing ERBB2 and potential therapeutic targets of the disease.

\section{Acknowledgments}

This work was supported by FAPESP-Fundação de Amparo a Pesquisa do Estado de São Paulo (02/01524-9 and 02/00093-4).

\section{References}

1. Holbro T, Civenni G and Hynes NE: The ErbB receptors and their role in cancer progression. Exp Cell Res 284: 99-110, 2003.

2. Casalini P, Iorio MV, Galmozzi E and Menard S: Role of HER receptors family in development and differentiation. J Cell Physiol 200: 343-350, 2004.

3. Hung M-C and Lau Y-K: Basic science of HER-2/neu: a review. Semin Oncol 26: 51-59, 1999.

4. Grant S, Qiao L and Dent P: Roles of ERBB family receptor tyrosine kinases, and downstream signaling pathways, in the control of cell growth and survival. Front Biosci 7: 376-389, 2002.

5. Tzahar E, Waterman H, Chen X, et al: A hierarchical network of interreceptor interactions determines signal transduction by Neu differentiation factor/neuregulin and epidermal growth factor. Mol Cell Biol 16: 5276-5287, 1996.

6. Yarden Y and Sliwkowski MX: Untangling the ErbB signalling network. Nat Rev Mol Cell Biol 2: 127-137, 2001.

7. Slamon DJ, Godophin W, Jones LA, et al: Studies of the HER-2/ neu proto-oncogene in human breast and ovarian cancer. Science 244: 707-712, 1989.

8. Ross JS and Fletcher JÁ: The HER-2/neu oncogene in breast cancer: prognostic factor, predictive factor, and target for therapy. Stem Cells 16: 413-428, 1998.

9. Benz CC, Scott GK, Sarup JC, et al: Estrogen-dependent, tamoxifen-resistant tumorigenic growth of MCF-7 cells transfected with HER2/neu. Breast Cancer Res Treat 24: 85-95, 1993.

10. Guy CT, Webster MA, Schaller M, Parsons TJ, Cardiff RD and Muller WJ: Expression of the neu protooncogene in the mammary epithelium of transgenic mice induces metastatic disease. Proc Natl Acad Sci USA 89: 10578-10582, 1992.

11. Chen J-S, Lan K and Hung M-C: Strategies to target HER/neu overexpression for cancer therapy. Drug Resistance Updates 6: 129-136, 2003.
12. Choudhury A, Charo J, Parapuram SK, Hunt RC, Hunt DM, Sleiger B and Kiessling R: Small interfering RNA (siRNA) inhibits the expression of the Her2/neu gene, upregulates HLA class I and induces apoptosis of Her2/neu positive tumor cell lines. Int J Cancer 108: 71-77, 2004.

13. Cobleigh MA, Vogel CL, Tripathy D, et al: Multinational study of the efficacy and safety of humanized anti-HER2 monoclonal antibody in women who have HER2-overexpressing metastatic breast cancer that has progressed after chemotherapy for metastatic disease. J Clin Oncol 17: 2639-2648, 1999.

14. Slamon DJ, Leyland-Jones B, Shak S, et al: Use of chemotherapy plus a monoclonal antibody against HER2 for metastatic breast cancer that overexpresses HER2. N Eng1 J Med 344: 783-792, 2001.

15. Hulit J, Lee RJ, Russell RG and Pestell RG: ErbB-2-induced mammary tumor growth: the role of cyclin D1 and p27Kip1. Biochem Pharmacol 64: 827-836, 2002.

16. Barbacci EG, Pustilnik LR, Rossi AM, et al: The biological and biochemical effects of CP-654577, a selective erbB2 kinase inhibitor, on human breast cancer cells. Cancer Res 63: 4450-4459, 2003.

17. Andrechek ER, Laing MA, Girgis-Gabardo AA, Siegel PM, Cardiff RD and Muller WJ: Gene expression profiling of neuinduced mammary tumors from transgenic mice reveals genetic and morphological similarities to ErbB2-expressing human breast cancers. Cancer Res 63: 4920-4926, 2003

18. Oh JJ, Grosshans DR, Wong SG and Slamon DJ: Identification of differentially expressed genes associated with HER-2/neu overexpression in human breast cancer cells. Nucleic Acids Res 27: 4008-4017, 1999.

19. Wilson KS, Roberts H, Leek R, Harris AL and Gerardts J: Differential gene expression patterns in HER2/neu-positive and negative breast cancer cell lines and tissues. Am J Pathol 161: 1171-1185, 2002.

20. Mackay A, Jones C, Dexter T, et al: cDNA microarray analysis of genes associated with ERBB2 (HER2/neu) overexpression in human mammary luminal epithelial cells. Oncogene 22: 2680-2688, 2003.

21. Kumar-Sinha C, Borie N, Ginester C, et al: Transcriptome analysis of HER2 reveals a molecular connection to fatty acid synthesis. Cancer Res 63: 132-139, 2003.

22. Bertucci F, Borie N, Ginestier C, et al: Identification and validation of an ERBB2 gene expression signature in breast cancers. Oncogene 23: 2564-2575, 2004.

23. Harris RA, Eichholtz TJ, Hiles ID, Page MJ and O'Hare MJ: New model of ErbB-2 over-expression in human mammary luminal epithelial cells. Int J Cancer 80: 477-484, 1999.

24. Stamps AC, Davies SC, Burman J and O'Hare MJ: Analysis of proviral integration in human mammary epithelial cell lines immortalized by retroviral infection with a temperaturesensitive SV40 T-antigen construct. Int J Cancer 57: 865-874, 1994.

25. Chomczynski P and Sacchi N: Single-step method of RNA isolation by acid guanidinium thiocyanate-phenol-chloroform extraction. Anal Biochem 162: 156-159, 1987.

26. Velculescu VE, Zhang L, Vogeltein B and Kinzler KW: Serial analysis of gene expression. Science 270: 484-487, 1995.

27. Pusztai L, Esteva FJ, Cristofanilli M, Hung MC and Hortobagvi GN: Chemo-signal therapy, an emerging new approach to modify drug resistance in breast cancer. Cancer Treat Rev 25: 271-277, 1999 .

28. Vivanco I and Sawyers CL: The phosphatidylinositol 3-kinase AKT pathway in human cancer. Nat Rev Cancer 2: 489-501, 2002.

29. Zhou BP and Hung MC: Dysregulation of cellular signaling by HER2/neu in breast cancer. Semin Oncol 30: 38-48, 2003.

30. Datta SR, Dudek H, Tao X, Masters S, Fu H, Gotoh Y and Greenberg ME: Akt phosphorylation of BAD couples survival signals to the cell-intrinsic death machinery. Cell 91: 231-241, 1997.

31. Brunet A, Park J, Tran H, Hu LS, Hemmings BA and Greenberg ME: Protein kinase SGK mediates survival signals by phosphorylating the forkhead transcription factor FKHRL1 (FOXO3a). Mol Cell Biol 21: 952-965, 2001.

32. Cowburn AS, Cadwallader KA, Reed BJ, Farahi N and Chilvers ER: Role of PI3-kinase-dependent Bad phosphorylation and altered transcription in cytokine-mediated neutrophil survival. Blood 100: 2607-2616, 2002.

33. Fink AL: Chaperone-mediated protein folding. Physiol Rev 79: 425-449, 1999. 
34. Soti C and Csermely P: Molecular chaperones in the etiology and therapy of cancer. Pathol Oncol Res 4: 316-321, 1998.

35. Pratt WB: The hsp90-based chaperone system: involvement in signal transduction from a variety of hormone and growth factor receptors. Proc Soc Exp Biol Med 217: 420-434, 1998.

36. Jaattela M: Escaping cell death: survival proteins in cancer. Exp Cell Res 248: 30-43, 1999.

37. Lewis J, Devin A, Miller A, Lin Y, Rodriguez Y, Neckers L and Liu ZG: Disruption of hsp90 function results in degradation of the death domain kinase, receptor-interacting protein (RIP), and blockage of tumor necrosis factor-induced nuclear factor-kappaB activation. J Biol Chem 275: 10519-10526, 2000.

38. Fortugno P, Beltrami E, Plescia J, Pradhan D, Marchisio PC, Sessa WC and Altieri DC: Regulation of survivin function by Hsp90. Proc Natl Acad Sci USA 100: 13791-13796, 2003.

39. Zhang R, Luo D, Miao R, Bai L, Ge Q, Sessa WC and Min W: Hsp90-Akt phosphorylates ASK1 and inhibits ASK1-mediated apoptosis. Oncogene 24: 3954-3963, 2005.

40. Basso AD, Solit DB, Munster PN and Rosen N: Ansamycin antibiotics inhibit Akt activation and cyclin D expression in breast cancer cells that overexpress HER2. Oncogene 21: 1159-1166, 2002.

41. Xu W, Yuan X, Jung YJ, et al: The heat shock protein 90 inhibitor geldanamycin and the ErbB inhibitor ZD1839 promote rapid PP1 phosphatase-dependent inactivation of AKT in ErbB2 overexpressing breast cancer cells. Cancer Res 63: 7777-7784, 2003.

42. Wei YQ, Zhao X, Kariya Y, Teshigawara K and Uchida A: Inhibition of proliferation and induction of apoptosis by abrogation of heat-shock protein (HSP) 70 expression in tumor cells. Cancer Immunol Immunother 40: 73-78, 1995.

43. Nylandsted J, Brand K and Jaattela M: Heat shock protein 70 is required for the survival of cancer cells. Ann NY Acad Sci 926: $122-125,2000$.

44. Wang G, Klostergaard J, Khodadadian M, et al: Murine cells transfected with human Hsp27 cDNA resist TNF-induced cytotoxicity. J Immunother Emphasis Tumor Immunol 19: 9-20, 1996.

45. Schepers H, Geugien M, van der Toorn M, Bryantsev AL, Kampinga $\mathrm{HH}$, Eggen BJ and Vallenga E: HSP27 protects AML cells against VP-16-induced apoptosis through modulation of p38 and c-Jun. Exp Hematol 33: 660-670, 2005.

46. Schultheiss T, Lin ZX, Lu MH, et al: Differential distribution of subsets of myofibrillar proteins in cardiac nonstriated and striated myofibrils. J Cell Biol 110: 1159-1172, 1990.

47. Edlund M, Lotano MA and Otey CA: Dynamics of alpha-actinin in focal adhesions and stress fibers visualized with alpha-actiningreen fluorescent protein. Cell Motil Cytoskeleton 48: 190-200, 2001.
48. Otey CA, Vasquez GB, Burridge K and Erickson BW: Mapping of the alpha-actinin binding site within the beta 1 integrin cytoplasmic domain. J Biol Chem 268: 21193-21197, 1993.

49. Miyamoto S, Teramoto H, Coso OA, Gutkind JS, Burbelo PD, Akiyama SK and Yamada KM: Integrin function: molecular hierarchies of cytoskeletal and signaling molecules. J Cell Biol 131: 791-805, 1995

50. Bhatt A, Kaverina I, Otey C and Huttenlocher A: Regulation of focal complex composition and disassembly by the calciumdependent protease calpain. J Cell Sci 115: 3415-3425, 2002.

51. Gluck U and Bem-Zeév A: Modulation of alpha-actinin levels affects cell motility and confers tumorigenicity on 3T3 cells. J Cell Sci 107: 1773-1782, 1994.

52. Hedjazifar S, Jenndahl LE, Shimokawa H and Baeckstrom D $\mathrm{PKB}$ mediates c-erbB2-induced epithelial beta1 integrin conformational inactivation through Rho-independent F-actin rearrangements. Exp Cell Res 307: 259-275, 2005

53. Ishikawa R, Yamashiro S and Matsumura F: Differential modulation of actin-severing activity of gelsolin by multiple isoforms of cultured rat cell tropomyosin. Potentiation of protective ability of tropomyosins by $83-\mathrm{kDa}$ nonmuscle caldesmon. J Biol Chem 264: 7490-7497, 1989.

54. Pawlak G and Helfman DM: Cytoskeletal changes in cell transformation and tumorigenesis. Curr Opin Genet Dev 11: 41-47 2001.

55. Bhattacharya B, Prasad GL, Valverius EM, Salomon DS and Cooper HL: Tropomyosins of human mammary epithelial cells: consistent defects of expression in mammary carcinoma cell lines. Cancer Res 50: 2105-2112, 1990.

56. Cooper HL, Feuerstein N, Noda M and Bassin RH: Suppression of tropomyosin synthesis, a common biochemical feature of oncogenesis by structurally diverse retroviral oncogenes. Mol Cell Biol 5: 972-983, 1985.

57. Prasad GL, Fuldner RA and Cooper HL: Expression of transduced tropomyosin 1 cDNA suppresses neoplastic growth of cells transformed by the ras oncogene. Proc Natl Acad Sci USA 90: 7039-7043, 1993.

58. Raval GN, Bharadwaj S, Levine EA, Willingham MC, Geary RL, Kute T and Prassad GL: Loss of expression of tropomyosin-1, a novel class II tumor suppressor that induces anoikis, in primary breast tumors. Oncogene 22: 6194-6203, 2003.

59. Mahadev K, Raval G, Bharadwaj S, et al: Suppression of the transformed phenotype of breast cancer by tropomyosin-1. Exp Cell Res 279: 40-51, 2002.

60. Feldner JC and Brandt BH: Cancer cell motility - on the road from c-erbB-2 receptor steered signaling to actin reorganization. Exp Cell Res 272: 93-108, 2002.

Table II supplementary. List of the genes down-regulated in C5.2 vs. HB4a mammary cells.

\begin{tabular}{|c|c|c|c|c|c|}
\hline TAG & UniGene & Description (locus name) & $\mathrm{HB} 4 \mathrm{a}$ & C5.2 & $\begin{array}{l}\text { Chromosome } \\
\text { region }\end{array}$ \\
\hline AAAATATTTT & Hs.509765 & Actinin, alpha 1 (ACTN1) & 23.00 & 1.02 & $14 \mathrm{q} 24.1-\mathrm{q} 24.2$ \\
\hline AAAGCCAAGA & Hs.74047 & Electron-transfer-flavoprotein, beta polypeptide (ETFB) & 18.00 & 0.00 & $19 \mathrm{q} 13.3$ \\
\hline AAGTGAGATG & Hs.272822 & RuvB-like 1 (E. coli) (RUVBL1) & 15.00 & 0.00 & $3 q 21$ \\
\hline AAGAGTTACG & Hs. 55041 & Mitochondrial ribosomal protein L2 (MRPL2) & 15.00 & 1.02 & $6 \mathrm{p} 21.3$ \\
\hline AGTGTGATAC & Hs.118820 & Hypothetical protein BC007882 (LOC152217) & 14.00 & 1.02 & $3 q 29$ \\
\hline AGGAAAAGAT & Hs.523829 & Polymerase (DNA-directed), delta 4 (POLD4) & 12.00 & 1.02 & $11 \mathrm{q} 13$ \\
\hline CTTGACATAC & Hs.171695 & Dual specificity phosphatase 1 (DUSP1) & 12.00 & 1.02 & $5 q 34$ \\
\hline AGGGCTACGG & BF571807 & EST & 12.00 & 1.02 & \\
\hline CCAGCCCAGC & Hs.29802 & Slit homolog 2 (Drosophila) (SLIT2) & 11.00 & 1.02 & $4 \mathrm{p} 15.2$ \\
\hline ACTGCGAGGA & Hs.110477 & Dolichyl-phosphate mannosyltransferase polypeptide 3 (DPM3) & 10.00 & 0.00 & $1 \mathrm{q} 22$ \\
\hline GGCCTTTTTT & Hs.75307 & H1 histone family, member X (H1FX) & 10.00 & 1.02 & $3 q 21.3$ \\
\hline CTACGTGCTC & Hs. 521056 & $\begin{array}{l}\text { ATP synthase, } \mathrm{H}+\text { transporting, mitochondrial F0 complex, } \\
\text { subunit } \mathrm{f} \text {, isoform } 2 \text { (ATP5J2) }\end{array}$ & 9.00 & 1.02 & $7 q 22.1$ \\
\hline AATTTGCAAC & Hs.420272 & H2A histone family, member Y (H2AFY) & 9.00 & 1.02 & $5 q 31.3-q 32$ \\
\hline CTTGATTCCC & Hs.518374 & Quiescin Q6 (QSCN6) & 9.00 & 1.02 & 1q24 \\
\hline CACTTGAAAA & Hs.7753 & Calumenin (CALU) & 9.00 & 1.02 & $7 q 32$ \\
\hline TTGGGAGCAG & Hs.445403 & Isoleucine-tRNA synthetase (IARS) & 9.00 & 1.02 & $9 q 21$ \\
\hline
\end{tabular}


Table II supplementary. Continued.

\begin{tabular}{|c|c|c|c|c|c|}
\hline TAG & UniGene & Description (locus name) & HB4a & $\mathrm{C} 5.2$ & $\begin{array}{l}\text { Chromosome } \\
\text { region }\end{array}$ \\
\hline ACGATTGATG & Hs. 528320 & Apolipoprotein A-I binding protein (APOA1BP) & 9.00 & 1.02 & $1 \mathrm{q} 22$ \\
\hline AAAATAAAAA & Hs. 517373 & Protoporphyrinogen oxidase (PPOX) & 9.00 & 1.02 & $1 \mathrm{q} 22$ \\
\hline CGTTCCTGCG & Hs.504609 & $\begin{array}{l}\text { Inhibitor of DNA binding 1, dominant negative helix-loop-helix } \\
\text { protein (ID1) }\end{array}$ & 9.00 & 1.02 & $20 q 11$ \\
\hline ATGTGAAGAG & Hs.111779 & Secreted protein, acidic, cysteine-rich (osteonectin) (SPARC) & 141.00 & 17.34 & $5 q 31.3-q 32$ \\
\hline GATCCCAAAC & BF686592 & EST & 8.00 & 0.00 & \\
\hline TTCTTGCTTA & Hs. 425777 & Ubiquitin-conjugating enzyme E2L 6 (UBE2L6) & 8.00 & 0.00 & $11 \mathrm{q} 12$ \\
\hline AAGAAAACTG & Hs. 352671 & Crystallin, zeta (quinone reductase)-like 1 (CRYZL1) & 8.00 & 0.00 & $21 \mathrm{q} 21.3$ \\
\hline CTTGGTTCTC & Hs. 501578 & Shadow of prion protein (Sprn) & 8.00 & 0.00 & $10 q 26.3$ \\
\hline AATACCTCGT & Hs. 414579 & Scotin (SCOTIN) & 8.00 & 0.00 & $3 \mathrm{p} 21.31$ \\
\hline GTTGCTGCCC & Hs.9234 & Seven transmembrane domain protein (NIFIE14) & 8.00 & 0.00 & $19 q 13.1$ \\
\hline TTAAAGATTT & Hs.133892 & Tropomyosin 1 (alpha) (TPM1) & 8.00 & 0.00 & $15 q 22.1$ \\
\hline GCCAAGATGC & Hs.515164 & $\begin{array}{l}\text { Growth arrest and DNA-damage-inducible, gamma interacting } \\
\text { protein } 1 \text { (GADD45GIP1) }\end{array}$ & 16.00 & 2.04 & $19 \mathrm{p} 13.13$ \\
\hline AАCATTCTAA & Hs. 530436 & Syntaxin binding protein 3 (STXBP3) & 8.00 & 1.02 & $1 \mathrm{p} 13.3$ \\
\hline TATCAATATT & Hs. 213424 & Secreted frizzled-related protein 1 (SFRP1) & 8.00 & 1.02 & $8 \mathrm{p} 12-\mathrm{p} 11.1$ \\
\hline AAGGAGTCCC & Hs. 333427 & CD320 antigen (8D6A) & 8.00 & 1.02 & $19 \mathrm{p} 13.3-\mathrm{p} 13.2$ \\
\hline CTCTAGAACC & Hs.292579 & Phosphatidylserine synthase 1 (PTDSS1) & 8.00 & 1.02 & $8 \mathrm{q} 22$ \\
\hline GCATCTGTTT & Hs.520189 & ELOVL family member 5, elongation of long chain fatty acids (ELOVL5) & 8.00 & 1.02 & $6 \mathrm{p} 21.1-\mathrm{p} 12.1$ \\
\hline AACCAGAGGT & T69505 & EST & 8.00 & 1.02 & \\
\hline TAACAAAGAA & Hs. 405537 & $\begin{array}{l}\text { Protein kinase, interferon-inducible double stranded RNA } \\
\text { dependent activator (PRKRA) }\end{array}$ & 8.00 & 1.02 & $2 \mathrm{q} 31.2$ \\
\hline GAATAAAATA & Hs.269592 & Putative NFKB activating protein (FLJ20241) & 8.00 & 1.02 & $19 \mathrm{p} 13.12$ \\
\hline GACTCTTCAG & Hs.534293 & $\begin{array}{l}\text { Serine (or cysteine) proteinase inhibitor, clade A (alpha-1 } \\
\text { antiproteinase, antitrypsin), member } 3 \text { (SERPINA3) }\end{array}$ & 8.00 & 1.02 & $14 q 32.1$ \\
\hline TGATTTATTC & Hs. 465870 & Kelch-like ECH-associated protein 1 (KEAP1) & 8.00 & 1.02 & $19 \mathrm{p} 13.2$ \\
\hline ATGGCAACAG & Hs. 505654 & Integrin, alpha 5 (fibronectin receptor, alpha polypeptide) (ITGA5) & 8.00 & 1.02 & $12 q 11-q 13$ \\
\hline TGGCTTAAAT & Hs. 521171 & Hypoxia-inducible protein 2 (HIG2) & 8.00 & 1.02 & $7 \mathrm{q} 32.2$ \\
\hline AAAGTGCATC & Hs.193326 & Fibroblast growth factor receptor-like 1 (FGFRL1) & 8.00 & 1.02 & $4 \mathrm{p} 16$ \\
\hline GACCTCCTGC & Hs. 502872 & Mitogen-activated protein kinase kinase kinase 11 (MAP3K11) & 8.00 & 1.02 & $11 \mathrm{q} 13.1-\mathrm{q} 13.3$ \\
\hline GATTTCAACC & Hs.371698 & RNA export 1 homolog (S.pombe) (RAE1) & 7.00 & 0.00 & $20 q 13.32$ \\
\hline GTGGGGGGAG & Hs. 446374 & HLA class II region expressed gene KE2 (HKE2) & 7.00 & 0.00 & $6 \mathrm{p} 21.3$ \\
\hline AATGACTGAA & Hs.93659 & Protein disulfide isomerase-associated 4 (ERP70) & 7.00 & 0.00 & $7 q 35$ \\
\hline ATGCGGGAGA & Hs. 534521 & Beta-casein-like protein (BCLP) & 7.00 & 0.00 & 1p35-p34 \\
\hline САСТСТАТСС & Hs. 258551 & Aspartyl aminopeptidase (DNPEP) & 7.00 & 0.00 & $2 \mathrm{q} 35$ \\
\hline TACAAACCTG & Hs.513626 & Metallothionein 1F (functional) (MT1F) & 7.00 & 0.00 & $16 q 13$ \\
\hline AGTATTCATA & Hs.466854 & Pregnancy specific beta-1-glycoprotein 5 (PSG5) & 7.00 & 0.00 & $19 q 13.2$ \\
\hline GGGGCTGTGG & Hs.371718 & General transcription factor IIIC, polypeptide 1, alpha 220 kDa (GTF3C1) & 7.00 & 0.00 & $16 \mathrm{p} 12$ \\
\hline AGGACAGAAG & Hs. 528670 & Matrix metalloproteinase 25 (MMP25) & 7.00 & 0.00 & $16 \mathrm{p} 13.3$ \\
\hline TCCТCТАССТ & Hs.32018 & SNAP-associated protein (SNAPAP) & 7.00 & 0.00 & $1 \mathrm{q} 21.3$ \\
\hline CACCTTGTGA & Hs. 515223 & cDNA FLJ14241 fis, clone OVARC1000533 & 7.00 & 0.00 & 19 \\
\hline ATACTTTAAT & Hs. 480653 & Annexin A5 (ANXA5) & 14.00 & 2.04 & $4 q 26-q 28$ \\
\hline TTTGGAGCAT & Hs.298198 & Chemokine-like factor super family 3 (CKLFSF3) & 7.00 & 1.02 & $16 q 22.1$ \\
\hline AATGGCACTT & Hs.26023 & Forkhead box J3 (FOXJ3) & 7.00 & 1.02 & 1pter-q31.3 \\
\hline АССТСТСТАА & Hs.94392 & Zinc finger protein 580 (ZNF580) & 7.00 & 1.02 & $19 q 13.42$ \\
\hline TATTTATTGA & Hs. 518250 & Coatomer protein complex, subunit gamma (COPG) & 7.00 & 1.02 & $3 \mathrm{q} 21.3$ \\
\hline GATTATGTAA & Hs.512597 & CGI-41 protein (CGI-41) & 7.00 & 1.02 & $1 \mathrm{q} 23.1$ \\
\hline GCTGGGGCCC & Hs.65256 & Leucine-rich repeat LGI family, member 4 (LGI4) & 7.00 & 1.02 & $19 q 13.12$ \\
\hline CACTTTTGGG & Hs. 334851 & LIM and SH3 protein 1 (LASP1) & 7.00 & 1.02 & $17 q 11-q 21.3$ \\
\hline CATTCAGTTG & Hs. 502773 & $\begin{array}{l}\text { Membrane-type } 1 \text { matrix metalloproteinase cytoplasmic tail binding } \\
\text { protein-1 (MTCBP-1) }\end{array}$ & 7.00 & 1.02 & $2 \mathrm{p} 25.2$ \\
\hline CCCAGCTGGA & Hs. 258798 & Chromosome 10 open reading frame 86 (C10orf86) & 7.00 & 1.02 & $10 q 26.13$ \\
\hline CGGGGTTCTT & Hs. 374262 & $\begin{array}{l}\text { Cofactor required for } \mathrm{Sp} 1 \text { transcriptional activation, subunit } 8,34 \mathrm{kDa} \\
\text { (CRSP8) }\end{array}$ & 7.00 & 1.02 & $9 q 34.1-q 34.3$ \\
\hline ACATAATAAA & Hs. 373550 & TGFB-induced factor (TALE family homeobox) (TGIF) & 7.00 & 1.02 & $18 \mathrm{p} 11.3$ \\
\hline GAAAGATGCT & Hs.398989 & Brain expressed X-linked 2 (BEX2) & 7.00 & 1.02 & $\mathrm{Xq} 22$ \\
\hline
\end{tabular}


Table II supplementary. Continued.

\begin{tabular}{|c|c|c|c|c|c|}
\hline TAG & UniGene & Description (locus name) & HB4a & C5.2 & $\begin{array}{l}\text { Chromosome } \\
\text { region }\end{array}$ \\
\hline AGACCATATT & Hs. 524899 & Sin3-associated polypeptide, $18 \mathrm{kDa}$ (SAP18) & 7.00 & 1.02 & $13 q 12.11$ \\
\hline AGTGTCTGTG & Hs.8867 & Cysteine-rich, angiogenic inducer, 61 (CYR61) & 7.00 & 1.02 & $1 \mathrm{p} 31-\mathrm{p} 22$ \\
\hline AGAAATAAAG & Hs.82927 & Adenosine monophosphate deaminase 2 (isoform L) (AMPD2) & 7.00 & 1.02 & $1 \mathrm{p} 13.3$ \\
\hline GAGCAAACGG & Hs.369785 & Hypothetical protein MGC2749 (MGC2749) & 7.00 & 1.02 & $19 \mathrm{p} 13.11$ \\
\hline TGGGAAGAGG & Hs.37982 & $\begin{array}{l}\text { Neural precursor cell expressed, developmentally down-regulated } 9 \\
\text { (NEDD9) }\end{array}$ & 7.00 & 1.02 & $6 \mathrm{p} 25-\mathrm{p} 24$ \\
\hline ATCTTGTTAC & Hs.203717 & Fibronectin 1 (FN1) & 34.00 & 5.10 & $2 q 34$ \\
\hline ATTAAAGAAT & Hs.22011 & C1q and tumor necrosis factor related protein 6 (C1QTNF6) & 13.00 & 2.04 & $22 \mathrm{q} 13.1$ \\
\hline AACTACATAG & Hs.9527 & Chromosome 2 open reading frame $28(\mathrm{C} 2$ orf 28$)$ & 19.00 & 3.06 & $2 \mathrm{p} 23.3$ \\
\hline AGTCTAGCTA & Hs. 170835 & Three prime repair exonuclease 2 (TREX2) & 6.00 & 0.00 & $\mathrm{Xq} 28$ \\
\hline AATGTTCTGT & Hs. 439200 & KIAA0090 (KIAA0090) & 6.00 & 0.00 & $1 \mathrm{p} 36.13$ \\
\hline GAATCTGGAG & Hs. 546348 & Leukotriene B4 12-hydroxydehydrogenase (LTB4DH) & 6.00 & 0.00 & $9 \mathrm{q} 31.3$ \\
\hline AGACCTCCTT & Hs. 412468 & Kelch domain containing 3 (KLHDC3) & 6.00 & 0.00 & $6 \mathrm{p} 21.1$ \\
\hline TTGACCCTGG & Hs.420559 & Phosphatidylserine decarboxylase (PISD) & 6.00 & 0.00 & $22 \mathrm{q} 12.2$ \\
\hline GTGCGGAGGA & Hs.332053 & Serum amyloid A1 (SAA1) & 6.00 & 0.00 & $11 \mathrm{p} 15.1$ \\
\hline GAGAATTAAA & Hs. 501140 & KIAA1598 (KIAA1598) & 6.00 & 0.00 & $10 \mathrm{q} 25.3$ \\
\hline GAGGACACAG & Hs.16426 & Podocalyxin-like (PODXL) & 6.00 & 0.00 & $7 q 32-q 33$ \\
\hline GAAAATAAAG & Hs. 531561 & Epithelial membrane protein 2 (EMP2) & 6.00 & 0.00 & $16 \mathrm{p} 13.2$ \\
\hline AAGGGGCAAG & Hs.332012 & Immunoglobulin superfamily, member 8 (IGSF8) & 6.00 & 0.00 & $1 \mathrm{q} 23.1$ \\
\hline AAAATAAAGC & Hs. 293818 & Nei like 2 (E. coli) (NEIL2) & 6.00 & 0.00 & $8 \mathrm{p} 23.1$ \\
\hline GAAATAAAGT & Hs. 482034 & Hypothetical protein FLJ21657 (FLJ21657) & 6.00 & 0.00 & $5 \mathrm{p} 12$ \\
\hline ATTCTTACAG & Hs.70312 & Cytochrome c oxidase subunit VIIa polypeptide 2 (liver) (COX7A2) & 6.00 & 0.00 & $6 q 12$ \\
\hline AGTCAGCTGG & Hs.26139 & Epidermal growth factor receptor pathway substrate 8 (EPS8) & 6.00 & 0.00 & $12 \mathrm{q} 13$ \\
\hline CTGATCCCCC & Hs.343571 & CCR4-NOT transcription complex, subunit 3 (CNOT3) & 6.00 & 0.00 & $19 \mathrm{q} 13.4$ \\
\hline TTGAATTCTT & Hs.288936 & Mitochondrial ribosomal protein L9 (MRPL9) & 6.00 & 0.00 & 1 \\
\hline AGGAAAGCTT & Hs.412601 & Zinc finger protein 527 (ZNF527) & 6.00 & 0.00 & $19 \mathrm{q} 13.1$ \\
\hline AAAAATAAAT & Hs.521124 & Mitochondrial ribosomal protein S28 (MRPS28) & 6.00 & 0.00 & $8 \mathrm{q} 21.1-\mathrm{q} 21.2$ \\
\hline ATTAATGAAT & Hs.18259 & XPA binding protein 1 (XAB1) & 6.00 & 0.00 & $2 \mathrm{p} 23.3$ \\
\hline AATACACATC & Hs.464734 & Small nuclear ribonucleoprotein D1 polypeptide $16 \mathrm{kDa}$ (SNRPD1) & 6.00 & 0.00 & $18 \mathrm{q} 11.2$ \\
\hline TTCACAGTGC & Hs. 437385 & Adaptin-ear-binding coat-associated protein 2 (FLJ10420) & 6.00 & 0.00 & $1 \mathrm{p} 36.13$ \\
\hline CGCATTAAAG & Hs.107101 & Hypothetical protein FLJ31031 (FLJ31031) & 6.00 & 0.00 & $1 \mathrm{p} 36.33$ \\
\hline TAACTAACAA & Hs. 152536 & Proteasome regulatory particle subunit p44S10 (P44S10) & 6.00 & 0.00 & $3 \mathrm{p} 14.1$ \\
\hline ACCGCCGTGG & Hs. 513803 & Cytochrome b-245, alpha polypeptide (CYBA) & 6.00 & 0.00 & $16 \mathrm{q} 24$ \\
\hline TACTCGGTTG & Hs.549298 & Hypothetical protein FLJ34236 (FLJ34236) & 6.00 & 0.00 & $12 \mathrm{q} 13.3$ \\
\hline GTTGGGTAGA & Hs.440263 & TP53 regulating kinase (TP53RK) & 6.00 & 0.00 & $20 \mathrm{q} 13.2$ \\
\hline TCTTCTAAAA & Hs. 108112 & Polymerase (DNA directed), epsilon 3 (p17 subunit) (POLE3) & 6.00 & 0.00 & $9 q 33$ \\
\hline TGTATTCAGC & Hs. 21765 & Fatty acid desaturase 3 (FADS3) & 6.00 & 0.00 & $11 q 12-q 13.1$ \\
\hline ATGGTTAAAG & Hs. 143728 & Wiskott-Aldrich syndrome-like (WASL) & 6.00 & 0.00 & $7 \mathrm{q} 31.3$ \\
\hline GCAATAATGG & Hs. 499620 & Gem (nuclear organelle) associated protein 4 (GEMIN4) & 12.00 & 2.04 & $17 \mathrm{p} 13$ \\
\hline CCTTGACCAA & Hs.369052 & Selenoprotein T (SELT) & 6.00 & 1.02 & $3 q 25.1$ \\
\hline TATACCAATC & Hs.379858 & Dimethylarginine dimethylaminohydrolase 1 (DDAH1) & 6.00 & 1.02 & $1 \mathrm{p} 22$ \\
\hline GACCAGCCCA & Hs.75799 & Protease, serine, 8 (prostasin) (PRSS8) & 6.00 & 1.02 & $16 \mathrm{p} 11.2$ \\
\hline AAGGGGAACT & Hs.180591 & Nucleoporin 35 kDa (NUP35) & 6.00 & 1.02 & $2 q 32.1$ \\
\hline AAGTGATTCT & Hs. 502829 & Splicing factor 1 (SF1) & 6.00 & 1.02 & $11 \mathrm{q} 13$ \\
\hline AGCGTGTGAT & Hs. 515259 & Single stranded DNA binding protein 4 (SSBP4) & 6.00 & 1.02 & $19 \mathrm{p} 13.1$ \\
\hline ATCCCTCAGT & Hs.496487 & $\begin{array}{l}\text { Activating transcription factor } 4 \text { (tax-responsive enhancer element } \\
\text { B67) (ATF4) }\end{array}$ & 6.00 & 1.02 & $22 \mathrm{q} 13.1$ \\
\hline GCCACTACCC & Hs.242458 & Spastic paraplegia 21 (autosomal recessive, Mast syndrome) (SPG21) & 6.00 & 1.02 & $15 q 21-q 22$ \\
\hline TGCCTGTGGT & Hs.370129 & Hypothetical gene supported by AK129923 (HMFNO672) & 6.00 & 1.02 & $8 \mathrm{p} 21.1$ \\
\hline GCTATGCTCC & Hs. 478469 & Presenilin associated, rhomboid-like (PSARL) & 6.00 & 1.02 & $3 q 27.1$ \\
\hline CAAGGAGATC & Hs.7471 & BBP-like protein 1 (BLP1) & 6.00 & 1.02 & $8 \mathrm{p} 11.23$ \\
\hline CAGCCTGGGG & Hs.72026 & Protease, serine, 21 (testisin) (PRSS21) & 6.00 & 1.02 & $16 \mathrm{p} 13.3$ \\
\hline CAGCTGTCCC & Hs.432448 & $\begin{array}{l}\text { Keratin } 16 \text { (focal non-epidermolytic palmoplantar keratoderma) } \\
\text { (KRT16) }\end{array}$ & 6.00 & 1.02 & $17 q 12-q 21$ \\
\hline TTCTTCTCGT & Hs. 474005 & SMT3 suppressor of mif two 3 homolog 3 (yeast) (SUMO3) & 6.00 & 1.02 & $21 \mathrm{q} 22.3$ \\
\hline CCCCCTCCGG & Hs.83753 & Small nuclear ribonucleoprotein polypeptides B and B1 (SNRPB) & 6.00 & 1.02 & $20 \mathrm{p} 13$ \\
\hline
\end{tabular}


Table II supplementary. Continued.

\begin{tabular}{|c|c|c|c|c|c|}
\hline TAG & UniGene & Description (locus name) & $\mathrm{HB} 4 \mathrm{a}$ & C5.2 & $\begin{array}{l}\text { Chromosome } \\
\text { region }\end{array}$ \\
\hline CCTGTCCAGT & Hs. 4253 & Hypothetical protein MGC2574 (MGC2574) & 6.00 & 1.02 & $11 \mathrm{q} 12.2$ \\
\hline GTCTAGTCAA & Hs. 129621 & KIAA0179 (KIAA0179) & 6.00 & 1.02 & $21 \mathrm{q} 22.3$ \\
\hline ACTGTTCTCT & Hs. 437831 & Chromosome 14 open reading frame 32 (C14orf32) & 6.00 & 1.02 & $14 q 22.2-q 22.3$ \\
\hline CCGAAAAAGT & Hs. 24763 & RAN binding protein 1 (RANBP1) & 6.00 & 1.02 & $22 q 11.21$ \\
\hline GGTCCTGTTC & Hs. 435255 & UBX domain containing 1 (UBXD1) & 6.00 & 1.02 & $19 \mathrm{p} 13$ \\
\hline AAATTGTTCC & Hs.531089 & Proteasome (prosome, macropain) subunit, alpha type, 3 (PSMA3) & 6.00 & 1.02 & $14 q 23$ \\
\hline AATATTGTCC & Hs.283322 & Hypothetical protein HSPC138 (HSPC138) & 6.00 & 1.02 & $11 \mathrm{q} 14.2$ \\
\hline TGGAAGAAAC & Hs.93235 & Chromosome 6 open reading frame 125 (C6orf125) & 17.00 & 3.06 & $6 \mathrm{p} 21.31$ \\
\hline CCCCCAATGC & Hs.115232 & Splicing factor 3a, subunit 2, 66 kDa (SF3A2) & 11.00 & 2.04 & $19 \mathrm{p} 13.3-\mathrm{p} 13.2$ \\
\hline TTGTCGATGG & Hs. 425801 & Dual specificity phosphatase 23 (DUSP23) & 11.00 & 2.04 & $1 \mathrm{q} 23.2$ \\
\hline AAAATAAAGA & Hs.73722 & APEX nuclease (multifunctional DNA repair enzyme) 1 (APEX1) & 75.00 & 14.28 & $14 q 11.2-q 12$ \\
\hline ATTTTGATAA & Hs. 472330 & Chromosome 20 open reading frame 3 (C20orf3) & 16.00 & 3.06 & 20p11.22-p11.21 \\
\hline GAGTGGAGAG & Hs. 410316 & H-rev107-like protein 5 (HRLP5) & 5.00 & 0.00 & $11 \mathrm{q} 13.2$ \\
\hline GAGTTCGACC & Hs. 348553 & Chromosome 19 open reading frame 33 (C19orf33) & 5.00 & 0.00 & $19 \mathrm{q} 13.2$ \\
\hline CATAATAGTG & CD102897 & EST & 5.00 & 0.00 & \\
\hline TATTAAAATA & Hs. 131683 & Cytoplasmic polyadenylation element binding protein 3 (CPEB3) & 5.00 & 0.00 & $10 \mathrm{q} 23.32$ \\
\hline GTCTTTAGGA & Hs.2057 & $\begin{array}{l}\text { Uridine monophosphate synthetase (orotate phosphoribosyl transferase } \\
\text { and orotidine-5'-decarboxylase) (UMPS) }\end{array}$ & 5.00 & 0.00 & $3 q 13$ \\
\hline CACAGGCAAA & Hs. 355983 & Basic leucine zipper and W2 domains 1 (BZW1) & 5.00 & 0.00 & $2 q 33$ \\
\hline CCCAGCAGTC & BE075489 & EST & 5.00 & 0.00 & \\
\hline CCCATCCGTC & AV649630 & EST & 5.00 & 0.00 & \\
\hline TAATTTAAAA & Hs.301613 & JTV1 gene (JTV1) & 5.00 & 0.00 & $7 \mathrm{p} 22$ \\
\hline GCCCAGCTCA & Hs.78466 & Proteasome (prosome, macropain) 26S subunit, non-ATPase, 8 (PSMD8) & 5.00 & 0.00 & $19 \mathrm{q} 13.2$ \\
\hline GAGGAGATGG & Hs. 546454 & Hypothetical protein DKFZp434N035 (DKFZp434N035) & 5.00 & 0.00 & $22 \mathrm{q} 11.21$ \\
\hline TTATATGAAA & Hs. 488624 & Postmeiotic segregation increased 2-like 2 (POM121) & 5.00 & 0.00 & $7 \mathrm{q} 11.23$ \\
\hline CCGCTGATCC & Hs. 492618 & Exostoses (multiple) 1 (EXT1) & 5.00 & 0.00 & $8 \mathrm{q} 24.11-\mathrm{q} 24.13$ \\
\hline GGCAGAGGGC & Hs. 477498 & Eukaryotic elongation factor, selenocysteine-tRNA-specific (SELB) & 5.00 & 0.00 & $3 \mathrm{q} 21.3$ \\
\hline ATTTAGTTGG & Hs. 268963 & Ubiquitin associated protein 1 (UBAP1) & 5.00 & 0.00 & 9 p22-p21 \\
\hline AATATTCATA & Hs.210385 & $\begin{array}{l}\text { Hect [homologous to the E6-AP (UBE3A) carboxyl terminus] domain } \\
\text { and RCC1 (CHC1)-like domain (RLD) } 1 \text { (HERC1) }\end{array}$ & 5.00 & 0.00 & $15 q 22$ \\
\hline TTTTAAAAAT & Hs. 370408 & Catechol-O-methyltransferase (COMT) & 5.00 & 0.00 & $22 \mathrm{q} 11.21-\mathrm{q} 11.23$ \\
\hline AGAACAGAAA & Hs.467898 & Adenylate cyclase 3 (ADCY3) & 5.00 & 0.00 & $2 \mathrm{p} 24-\mathrm{p} 22$ \\
\hline TTCTCTCCCC & Hs.106909 & Anaphase promoting complex subunit 13 (ANAPC13) & 5.00 & 0.00 & $3 q 22.1$ \\
\hline GATTTTCTAC & Hs.532399 & KIAA0663 gene product (KIAA0663) & 5.00 & 0.00 & $1 \mathrm{q} 32.1$ \\
\hline AAATCGATGA & Hs.496943 & Hypothetical protein MGC29729 (MGC29729) & 5.00 & 0.00 & $\mathrm{Xq} 28$ \\
\hline AGAGCATATC & Hs. 430425 & Guanine nucleotide binding protein ( $\mathrm{G}$ protein), beta polypeptide 1 (GNB1) & 5.00 & 0.00 & $1 \mathrm{p} 36.33$ \\
\hline TTCACCTGTG & AW833547 & EST & 5.00 & 0.00 & \\
\hline TCTCTGCTCA & Hs. 515134 & CTL2 protein (CTL2) & 5.00 & 0.00 & $19 \mathrm{p} 13.1$ \\
\hline TCTGTCCTCA & Hs.272062 & Protein tyrosine phosphatase, receptor type, F (PTPRF) & 5.00 & 0.00 & $1 \mathrm{p} 34$ \\
\hline TTCCGTTTCT & Hs.288969 & HSCARG protein (HSCARG) & 5.00 & 0.00 & $16 \mathrm{p} 13.3$ \\
\hline AACCAATACA & Hs. 146161 & Endothelin converting enzyme 2 (ECE2) & 5.00 & 0.00 & 3 \\
\hline CGCCGAACAC & BF127130 & EST & 5.00 & 0.00 & \\
\hline GTGCCCTTGA & BF308334 & EST & 5.00 & 0.00 & \\
\hline AAGATAAACT & Hs. 426324 & Tumor suppressor candidate 3 (TUSC3) & 5.00 & 0.00 & $8 \mathrm{p} 22$ \\
\hline GGATGCAATG & BI192884 & EST & 5.00 & 0.00 & \\
\hline TAGGGCTCTC & Hs. 524571 & Cell division cycle associated 8 (CDCA8) & 5.00 & 0.00 & $1 \mathrm{p} 34.3$ \\
\hline AAATAAAGAT & Hs.146766 & cDNA FLJ41437 fis, clone BRHIP2007928 & 5.00 & 0.00 & 22 \\
\hline TATTGTATAT & Hs.461896 & V-crk sarcoma virus CT10 oncogene homolog (avian) (CRK) & 5.00 & 0.00 & $17 \mathrm{p} 13.3$ \\
\hline AGCCCTCCTG & BI089668 & EST & 5.00 & 0.00 & \\
\hline AACTTACAGA & Hs. 532755 & Likely ortholog of mouse gene trap locus 3 (GTL3) & 5.00 & 0.00 & $16 \mathrm{q} 21$ \\
\hline TCCCACGTTC & Hs. 534465 & Presenilin enhancer 2 homolog (C. elegans) (PEN2) & 5.00 & 0.00 & $19 \mathrm{q} 13.12$ \\
\hline CTTTTCAAGA & Hs.510402 & $\begin{array}{l}\text { Membrane cofactor protein (CD46, trophoblast-lymphocyte cross- } \\
\text { reactive antigen) }(\mathrm{MCP})\end{array}$ & 5.00 & 0.00 & $1 q 32$ \\
\hline TTACТСТTТС & Hs. 2533 & Aldehyde dehydrogenase 9 family, member A1 (ALDH9A1) & 5.00 & 0.00 & $1 \mathrm{q} 23.1$ \\
\hline CCTGGTCCAA & AA650073 & EST & 20.00 & 4.08 & \\
\hline ACCTTCCTAG & Hs.6454 & Regulator of G-protein signalling 19 interacting protein 1 (RGS19IP1) & 15.00 & 3.06 & $19 \mathrm{p} 13.1$ \\
\hline
\end{tabular}


Table II supplementary. Continued.

TAG UniGene Description (locus name)
$\begin{array}{ccc}\text { HB4a } & \text { C5.2 } & \begin{array}{c}\text { Chromosome } \\ \text { region }\end{array}\end{array}$

GAACGCCTAA Hs.173381

AATCTTGTTT Hs.417795

TATGCTTAGT Hs.444818

ATCTCTTTCC Hs.355570

TGCCTCTGTC Hs.75514

AAGAAGCAGG Hs.523262

ACTAACTGTG Hs.16003

GTGTAGTTGA BI464015

AACTCTGGAC Hs.134406

GTGCCCGTGC Hs.524219

AAGGATGCGG Hs.112444

CTGCCCCCAC Hs.164410

ACCAGCTCCC Hs.22546

CTTTTCTTCT Hs.479814

TCCAGGGCTC Hs.22824

GAGGCATATG Hs.553531

GAGTGAAAGA Hs.5811

ATCTTAAACA Hs.473838

CACGAAGATG Hs.150693

GGAAGATGTT Hs.288284

TTCACAGATT Hs.431101

GGCCAAACAG Hs.520149

GGCCCCAAAG AI608743

CCATCCGAAA AW799595

TACACAGAAC Hs.24283

CGCCTTTACT Hs.47062

CTCCATCGGC Hs.65238

AATTAACTCC Hs.436219

TTGAATCCCC Hs.112341

GAAATGCCTT Hs.252682

AGATCCTACT Hs.546253

TCAGAGAAGG Hs.534350

GACTTGGCCC Hs.473648

TCTTCCCCAG Hs.529132

ATCTTAGTCA Hs.465763

ATGGTTCTCA Hs.440382

GGAGTGTGCT Hs.504687

CCCTAGGTTG Hs.3989

TTTTAATGTA Hs.352341

GTCCCTCTCA Hs.459857

CGCTGTGGGG Hs.7486

CGTTCATTCA Hs.216226

CTTCCGTAGC Hs.436417

ACCTCCCACC Hs.118666

ACTGACTATC Hs.520037

AGGGGAATGG Hs.441737

TCTAAAAAGG Hs.16622

ATTACACCAC Hs.512607

TGTTCTGCTA AW367805

CCAAGGAATG Hs.469941

AAATAGGTTT Hs.419640

GGTGTGGGTG BC039061

AACATCAAAC Hs.518609
Stromal cell-derived factor 2-like 1 (DPYSL2)

Dermokine (ZD52F10)

CGG triplet repeat binding protein 1 (CGGBP1)

Hypothetical protein FLJ30656 (FLJ30656)

Nucleoside phosphorylase (NP)

Chromosome 1 open reading frame 8 (C1orf8)

Retinoblastoma binding protein 4 (RBBP4)

EST

Thioredoxin-like 4B (TXNL4B)

Triosephosphate isomerase 1 (TPI)

TAF11 RNA polymerase II, TATA box binding protein (TBP)-

associated factor, $28 \mathrm{kDa}$ (TAF11)

Chromosome 16 open reading frame 7 (C16orf7)

Cytochrome b, ascorbate dependent 3 (CYBASC3)

Polymerase (RNA) II (DNA directed) polypeptide B, 140 kDa (POLR2B)

MYB binding protein (P160) 1a (MYBBP1A)

CGI-96 protein (CGI-96)

Chromosome 21 open reading frame 59 (C21 orf59)

Down syndrome critical region gene 2 (DSCR2)

Activated leukocyte cell adhesion molecule (ALCAM)

PQ loop repeat containing 1 (PQLC1)

Guanine nucleotide binding protein (G protein), gamma 12 (GNG12)

Mitochondrial ribosomal protein S18A (MRPS18A)

EST

EST

Zinc finger, DHHC-type containing 20 (FLJ25952)

Polymerase (RNA) II (DNA directed) polypeptide I, $14.5 \mathrm{kDa}$ (POLR2I)

Ring finger protein 40 (RNF40)

Aldehyde dehydrogenase 1 family, member B1 (ALDH1B1)

Protease inhibitor 3, skin-derived (SKALP) (PI3)

Torsin family 1, member B (torsin B) (TOR1B)

Farnesyl-diphosphate farnesyltransferase 1 (FDFT1)

SWI/SNF related, matrix associated, actin dependent regulator of

chromatin, subfamily b, member 1(SMARCB1)

Phosphoribosylglycinamide formyltransferase, phosphoribosylglycinamide synthetase, phosphoribosylaminoimidazole synthetase (GART)

Selenoprotein W, 1 (SEPW1)

Rho/rac guanine nucleotide exchange factor (GEF) 18 (ARHGEF18)

Ret finger protein (RFP)

Elongation factor Tu family protein (MYL9)

Plexin B2 (PLXNB2)

Stress 70 protein chaperone, microsome-associated, $60 \mathrm{kDa}(\mathrm{STCH})$

Calcium regulated heat stable protein 1,24 kDa (CARHSP1)

Ethylmalonic encephalopathy 1 (ETHE1)

Synaptogyrin 1 (SYNGR1)

Decreased expression in renal and prostate (DERPC)

FAD-synthetase (PP591)

Sialidase 1 (lysosomal sialidase) (NEU1)

Junctophilin 2 (JPH2)

Zinc finger protein 185 (LIM domain) (ZNF185)

Membrane interacting protein of RGS16 (MIR16)

EST

Hypothetical protein LOC130074 (LOC130074)

Parkinson disease (autosomal recessive, early onset) 7 (PARK7)

EST

Actin related protein 2/3 complex, subunit 5, $16 \mathrm{kDa}$ (ARPC5)

$\begin{array}{rrc}10.00 & 2.04 & 8 \mathrm{p} 22-\mathrm{p} 21 \\ 10.00 & 2.04 & 19 \mathrm{q} 13.12 \\ 10.00 & 2.04 & 3 \mathrm{p} 12-\mathrm{p} 11.1 \\ 10.00 & 2.04 & 17 \mathrm{q} 21.31 \\ 10.00 & 2.04 & 14 \mathrm{q} 13.1 \\ 10.00 & 2.04 & 1 \mathrm{p} 36-\mathrm{p} 31 \\ 10.00 & 2.04 & 1 \mathrm{p} 35.1 \\ 10.00 & 2.04 & \\ 5.00 & 1.02 & 16 \mathrm{q} 22.2 \\ 5.00 & 1.02 & 12 \mathrm{p} 13 \\ 5.00 & 1.02 & 6 \mathrm{p} 21.31 \\ & & \\ 5.00 & 1.02 & 16 \mathrm{q} 24 \\ 5.00 & 1.02 & 11 \mathrm{q} 12.2 \\ 5.00 & 1.02 & 4 \mathrm{q} 12\end{array}$

$\begin{array}{lll}5.00 & 1.02 \quad 17 \mathrm{p} 13.3\end{array}$

$5.00 \quad 1.02 \quad 22 \mathrm{q} 13.2-\mathrm{q} 13.31$

$\begin{array}{lll}5.00 & 1.02 \quad 21 \mathrm{q} 22.1\end{array}$

$\begin{array}{lll}5.00 & 1.02 \quad 21 \mathrm{q} 22.3\end{array}$

$\begin{array}{lll}5.00 & 1.02 \quad 3 q 13.1\end{array}$

$\begin{array}{lll}5.00 & 1.02 \quad 18 \mathrm{q} 23\end{array}$

$\begin{array}{lll}5.00 & 1.02 & 1 \mathrm{p} 31.2\end{array}$

$\begin{array}{lll}5.00 & 1.02 & 6 \mathrm{p} 21.3\end{array}$

$5.00 \quad 1.02$

$5.00 \quad 1.02$

$5.00 \quad 1.02$

$5.00 \quad 1.02$

$5.00 \quad 1.02$

$5.00 \quad 1.02$

$5.00 \quad 1.02$

$5.00 \quad 1.02$

$5.00 \quad 1.02$

$5.00 \quad 1.02$

$5.00 \quad 1.02$

13q12.11

$19 \mathrm{q} 12$

16p11.2-p11.1

$9 \mathrm{p} 11.1$

20q12-q13

$9 \mathrm{q} 34$

8p23.1-p22

$22 \mathrm{q} 11.23$

$21 \mathrm{q} 22.1$

$\begin{array}{ll}5.00 & 1.02\end{array}$

$5.00 \quad 1.02$

$5.00 \quad 1.02$

$5.00 \quad 1.02$

$5.00 \quad 1.02$

$5.00 \quad 1.02$

$5.00 \quad 1.02$

$5.00 \quad 1.02$

$5.00 \quad 1.02$

$5.00 \quad 1.02$

$5.00 \quad 1.02$

$5.00 \quad 1.02$

$5.00 \quad 1.02$

$5.00 \quad 1.02$

$5.00 \quad 1.02$

$5.00 \quad 1.02$

$5.00 \quad 1.02$

$5.00 \quad 1.02$

$5.00 \quad 1.02$

$5.00 \quad 1.02$
$19 q 13.3$

19p13.3

$6 \mathrm{p} 22$

20q11.23

22q13.33

21q11.1

16p13.2

19q13.31

22q13.1

16q 22.1

1q22

$6 \mathrm{p} 21.3$

20q13.12

$\mathrm{Xq} 28$

16p12-p11.2

$2 \mathrm{q} 21.2$

1p36.33-p36.12

1q25.3 
Table II supplementary. Continued.

\begin{tabular}{lll}
\hline TAG & UniGene & \multicolumn{1}{c}{ Description (locus name) } \\
\hline TTTTTACTCA & Hs.212395 & CDKN1A interacting zinc finger protein 1 (CIZ1) \\
CTAGCCCTCA & BF678697 & EST \\
TAAAAAAGGT & Hs.122934 & Hypothetical protein FLJ23861 (FLJ23861) \\
ACTATCTCTA & Hs.379754 & Hypothetical protein LOC340061 (LOC340061) \\
GAAACAATGG & Hs.553542 & Erythrocyte membrane protein band 4.1 like 4A (EPB41L4A) \\
TATGTATGTT & Hs.442592 & Casein kinase 1, alpha 1 (CSNK1A1) \\
AGATGTGTGG & Hs.515848 & $\begin{array}{l}\text { Hydroxyacyl-Coenzyme A dehydrogenase/3-ketoacyl-Coenzyme A thiolase/ } \\
\text { enoyl-Coenzyme A hydratase (trifunctional protein), beta subunit (HADHB) }\end{array}$
\end{tabular}

GACCACGAAT Hs.148641 GAGGATTTTA Hs.79088

GATAGGTCGG Hs.446075 TGGCCCCAGG Hs.110675 CAAGGTCATT Hs.510833 CCATCTCTAG BU955322 AGGAGCAAAG Hs.515785 GGAGGCAGGT Hs.474083

GTTTAAATCG TTTTCTGAAA

CTTCCTTGCC CCCCTCTGAG ATCCAGTCTG TGGAGAAAGA TAAAGTGTCT CTTATTCCTT

Hs.333786 Hs. 435136 Hs. 2785 Hs. 12341 Hs. 517029 Hs. 445394 Hs. 462550 Hs. 418533

CTTCTATGTA Hs.117825

GAGGGTATAC Hs.274184

CAGTCTCTCA Hs.539100 GGCTCCCACT Hs.509736 ATTCTGCCTC Hs.369279 ATGTACTAAA Hs.518123 TTTTATTAAA Hs.473788 ATTAAACCAT Hs.222494 TACTATTAAT Hs.6710 CAGGAGCCCC Hs.444202 GGCACTTATG CCGTCAAGGG GATAATTTTT ATTTTTGGTG Hs.513034 AA095497 Hs. 190722 Hs. 549585 GAATCAAGCT Hs.17296 GCTCTGGTGT Hs.445097 GCAAAAAAAT Hs.522310 CCAACCTTGG Hs.438409

AGATCTACAA Hs.514009 GTGAACACAG Hs.274135 TCAATAAATA Hs.4276 TGTGGCCCAC Hs.114198 TAAGGACGAG Hs.554886 TGTTCTATGA Hs.360033 TTAACAAAGA Hs.553497 GCCCACATCC Hs.84753 GAAATACACG BG960366 TTCATTATAG Hs.533514 GATGGCTGCT BE894663 AGAGCACTCT Hs.355263
Cathepsin H (CTSH)

Reticulocalbin 2, EF-hand calcium binding domain (RCN2)

Aconitase 1, soluble (ACO1)

Apolipoprotein C-I (APOC1)

Tight junction protein 1 (zona occludens 1) (TJP1)

EST

Biliverdin reductase B [flavin reductase (NADPH)] (BLVRB)

UDP-Gal:betaGlcNAc beta 1,4-galactosyltransferase, polypeptide 2 (BAGALT2)

Proteasome (prosome, macropain) subunit, alpha type, 2 (PSMA2)

Thioredoxin (TXN)

Keratin 17 (KRT17)

Adenosine deaminase, RNA-specific (ADAR)

Chromosome 20 open reading frame 102 (C20orf102)

Vacuolar protein sorting 29 (yeast) (VPS29)

Phosphatidylinositol glycan, class S (PIGS)

BUB3 budding uninhibited by benzimidazoles 3 homolog (yeast) (BUB3)

Poly(ADP-ribose) polymerase family, member 4 (PARP4)

Transcription factor binding to IGHM enhancer 3 (TFE3)

Ribosomal protein S10 (RPS10)

Heat shock $90 \mathrm{kDa}$ protein 1, beta (HSPCB)

NACHT, leucine rich repeat and PYD containing 2 (NALP2)

TRK-fused gene (TFG)

OTU domain, ubiquitin aldehyde binding 1 (OTUB1)

Hypothetical LOC79954 (FLJ14075)

Mannose-P-dolichol utilization defect 1 (MPDU1)

Solute carrier family 9 (sodium/hydrogen exchanger), isoform 8 (SLC9A8)

Unc-51-like kinase 3 (C. elegans) (ULK3)

EST

HSPC142 protein (HSPC142)

Prolyl endopeptidase-like (KIAA0436)

Potassium channel tetramerisation domain containing 14 (KCTD14)

Snf2-related CBP activator protein (SRCAP)

$\mathrm{N}$-acetylneuraminic acid synthase (sialic acid synthase) (NANS)

XPMC2 prevents mitotic catastrophe 2 homolog (Xenopus laevis) (XPMC2H)

Chromosome 17 open reading frame 35 (C17orf35)

Hypothetical protein DKFZp434K1815 (DKFZp434K1815)

Basic helix-loop-helix domain containing, class B, 9 (BHLHB9)

Mitogen-activated protein kinase kinase 5 (MAP2K5)

Hypothetical protein FLJ22457 (FLJ22457)

DNA replication complex GINS protein PSF1 (KIAA0186)

Phosphatidylinositol glycan, class H (PIGH)

Hypothetical protein FLJ12442 (FLJ12442)

EST

Acetylserotonin O-methyltransferase-like (ASMTL)

EST

Transcribed locus HB4a C5.2 Chromosome
region

$\begin{array}{ccc}5.00 & 1.02 & 9 \mathrm{q} 34.1 \\ 5.00 & 1.02 & \\ 5.00 & 1.02 & 2 \mathrm{q} 34 \\ 5.00 & 1.02 & 5 \mathrm{q} 31.2 \\ 5.00 & 1.02 & 5 \mathrm{q} 22.2 \\ 5.00 & 1.02 & 5 \mathrm{q} 32 \\ 5.00 & 1.02 & 2 \mathrm{p} 23\end{array}$

$\begin{array}{lll}5.00 & 1.02 \quad 15 q 24-q 25\end{array}$

$\begin{array}{lll}5.00 & 1.02 \quad 15 \mathrm{q} 23\end{array}$

$\begin{array}{lll}5.00 & 1.02 \quad 9 \mathrm{p} 22-\mathrm{q} 32\end{array}$

$\begin{array}{lll}5.00 & 1.02 & 19 \mathrm{q} 13.2\end{array}$

$\begin{array}{lll}5.00 & 1.02 \quad 15 \mathrm{q} 13\end{array}$

$5.00 \quad 1.02$

$\begin{array}{lll}24 & 5.1 & 19 \mathrm{q} 13.1-\mathrm{q} 13.2\end{array}$

$14 \quad 3.06 \quad 1 \mathrm{p} 34-\mathrm{p} 33$

$18 \quad 4.08 \quad 7 \mathrm{p} 14.1$

$\begin{array}{lll}18 & 4.08 & 9 \mathrm{q} 31\end{array}$

$9 \quad 2.04 \quad 17 \mathrm{q} 12-\mathrm{q} 21$

$9 \quad 2.04 \quad 1 \mathrm{q} 21.1-\mathrm{q} 21.2$

$\begin{array}{lll}9 & 2.04 & 20 \mathrm{q} 11.23\end{array}$

$\begin{array}{lll}9 & 2.04 & 12 \mathrm{q} 24\end{array}$

$\begin{array}{lll}9 & 2.04 & 17 \mathrm{p} 13.2\end{array}$

$\begin{array}{lll}9 & 2.04 & 10 \mathrm{q} 26\end{array}$

$\begin{array}{lll}9 & 2.04 & 13 q 11\end{array}$

$9 \begin{array}{lll}9.04 & \mathrm{Xp} 11.22\end{array}$

$\begin{array}{lll}61 & 14.3 & 6 \mathrm{p} 21.31\end{array}$

$\begin{array}{lll}13 & 3.06 & 6 \mathrm{p} 12\end{array}$

$\begin{array}{lll}13 & 3.06 & 19 \mathrm{q} 13.42\end{array}$

$\begin{array}{lll}13 & 3.06 & 3 \mathrm{q} 12.2\end{array}$

$\begin{array}{lll}17 & 4.08 & 11 \mathrm{q} 13.1\end{array}$

2p25.1

17p13.1-p12

20q13.13

$15 \mathrm{q} 24.1$

$19 \mathrm{p} 13.11$

$2 \mathrm{p} 22.1$

$11 \mathrm{q} 14.1$

$16 \mathrm{p} 11.2$

9p24.1-p23

9q34.2

$17 \mathrm{p} 11.2$

$7 \mathrm{q} 22.1$

$\mathrm{Xq} 23$

$15 \mathrm{q} 23$

$1 \mathrm{p} 13.3$

$20 \mathrm{p} 11.21$

14q11-q24

$3 \mathrm{p} 21.1$

Xp22.3

4 
Table II supplementary. Continued.

\begin{tabular}{|c|c|c|c|c|c|}
\hline TAG & UniGene & Description (locus name) & HB4a & C5.2 & $\begin{array}{l}\text { Chromosome } \\
\text { region }\end{array}$ \\
\hline CAAAGGAATC & AA089931 & EST & 4 & 0 & \\
\hline TTTTTACAGT & Hs. 477155 & ATPase, $\mathrm{H}+$ transporting, lysosomal $70 \mathrm{kDa}, \mathrm{V} 1$ subunit A (ATP6V1A) & 4 & 0 & $3 q 13.2-q 13.31$ \\
\hline TTCTGAAGAC & Hs. 477352 & Protein disulfide isomerase family A, member 5 (PDIR) & 4 & 0 & $3 q 21.1$ \\
\hline CCACTGCATT & Hs. 513102 & SCAN domain containing 2 (SCAND2) & 4 & 0 & $15 q 25-q 26$ \\
\hline TCACAAAAGA & Hs.12646 & Poly(ADP-ribose) polymerase family, member 12 (ZC3HDC1) & 4 & 0 & $7 q 34$ \\
\hline TGAGTTTTAC & Hs.58373 & Hypothetical protein LOC283951 (LOC283951) & 4 & 0 & $16 \mathrm{p} 13.3$ \\
\hline GAGAGGACAT & Hs.403933 & F-box protein 32 (FBX032) & 4 & 0 & $8 \mathrm{q} 24.13$ \\
\hline ССССТССССА & Hs. 150540 & Hypothetical protein BC002942 (BC002942) & 4 & 0 & $22 q 13.33$ \\
\hline TACATCATAA & Hs.122386 & cDNA FLJ30952 fis, clone HCASM1000130 & 4 & 0 & 8 \\
\hline СТTTTCTTAT & AA610382 & EST & 4 & 0 & \\
\hline CAGAGTGACT & Hs.506652 & PWP1 homolog (S. cerevisiae) (PWP1) & 4 & 0 & $12 \mathrm{q} 23.3$ \\
\hline CAGCATCTGG & Hs.98669 & ADP-ribosylhydrolase like 1 (ADPRHL1) & 4 & 0 & $13 q 34$ \\
\hline CAGCTTCCCT & Hs.528024 & $\begin{array}{l}\text { Microtubule associated monoxygenase, calponin and LIM domain containing } 3 \\
\text { (MICAL3) }\end{array}$ & 4 & 0 & 22q11.21 \\
\hline GTTAAGATTT & Hs.516954 & Rho guanine nucleotide exchange factor (GEF) 11 (ARHGEF11) & 4 & 0 & $1 \mathrm{q} 21$ \\
\hline AAAATGAAGA & Hs. 418520 & Chromosome 6 open reading frame 51 (C6orf51) & 4 & 0 & $6 \mathrm{q} 21$ \\
\hline АСТСТTCTAА & Hs.498397 & Saccharopine dehydrogenase (putative) (CGI-49) & 4 & 0 & $1 \mathrm{q} 44$ \\
\hline GTAATTACTT & Hs. 436502 & Hypothetical protein LOC51249 (LOC51249) & 4 & 0 & $1 \mathrm{p} 34.1$ \\
\hline AGAAATCACT & Hs.438289 & L-3-hydroxyacyl-Coenzyme A dehydrogenase, short chain (HADHSC) & 4 & 0 & $4 q 22-q 26$ \\
\hline TTCTAGACCA & Hs.372286 & Cullin 3 (CUL3) & 4 & 0 & $2 q 36.3$ \\
\hline AATTAATTGT & Hs.466391 & Chromosome 19 open reading frame 2 (C19orf2) & 4 & 0 & $19 \mathrm{q} 12$ \\
\hline CCTGGGTCCC & Hs.287692 & CD33 antigen-like 3 (CD33L3) & 4 & 0 & $18 \mathrm{q} 12.3$ \\
\hline TTTTTTACAA & Hs. 546316 & Phosphatidylinositol-4-phosphate 5-kinase, type I, alpha (PIP5K1A) & 4 & 0 & $1 q 22-q 24$ \\
\hline ATATCTTTGC & Hs.464985 & Ras-like without CAAX 2 (RIT2) & 4 & 0 & $18 \mathrm{q} 12.3$ \\
\hline TTGAAATAAA & Hs.418581 & FLJ20160 protein (FLJ20160) & 4 & 0 & $2 \mathrm{q} 32.2$ \\
\hline GTGAGGGCAC & Hs.107382 & DEAH (Asp-Glu-Ala-His) box polypeptide 37 (DHX37) & 4 & 0 & $12 \mathrm{q} 24.31$ \\
\hline ACAGGTGGAG & BI059321 & EST & 4 & 0 & \\
\hline GGAACTTCCA & Hs.75782 & General transcription factor IIIC, polypeptide 2, beta $110 \mathrm{kDa}(\mathrm{GTF} 3 \mathrm{C} 2)$ & 4 & 0 & $2 \mathrm{p} 23.3$ \\
\hline TCAGAGTCTT & BQ331290 & 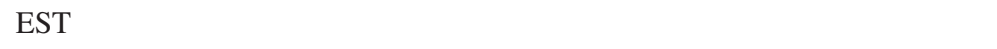 & 4 & 0 & \\
\hline GACTTACTAT & Hs.20848 & WD repeat, SAM and U-box domain containing 1 (WDSAM1) & 4 & 0 & $2 \mathrm{q} 24.2$ \\
\hline AAGAAAAGAA & Hs.299208 & Coenzyme Q3 homolog, methyltransferase (yeast) (COQ3) & 4 & 0 & $6 q 16.3$ \\
\hline ACCCACTCTA & Hs.352614 & PLSC domain containing protein (LOC254531) & 4 & 0 & $15 \mathrm{q} 14$ \\
\hline GCCACCCCGT & Hs. 461047 & Glucose-6-phosphate dehydrogenase (G6PD) & 4 & 0 & $\mathrm{Xq} 28$ \\
\hline TTAATACAAT & Hs. 126115 & Phosphatidylinositol glycan, class B (PIGB) & 4 & 0 & $15 \mathrm{q} 21-\mathrm{q} 22$ \\
\hline TCCTACAATC & Hs. 556063 & Opposite strand transcription unit to STAG3 (GATS) & 4 & 0 & $7 \mathrm{q} 22.1$ \\
\hline AAAAATCCTA & Hs.116014 & Chromosome 14 open reading frame 126 (C14orf126) & 4 & 0 & $14 \mathrm{q} 12$ \\
\hline GAAACAAGAA & Hs.285887 & UDP glycosyltransferase 2 family, polypeptide B4 (UGT2B4) & 4 & 0 & $4 q 13$ \\
\hline AGTAAGCTCC & Hs.172788 & Armadillo repeat containing, X-linked 3 (ARMCX3) & 4 & 0 & $\mathrm{Xq} 21.33-\mathrm{q} 22.2$ \\
\hline AGTAATTCTT & T61002 & EST & 4 & 0 & \\
\hline GTAATAAAGG & BF246877 & EST & 4 & 0 & \\
\hline TGGCCAGCTC & Hs. 477128 & Steroid sensitive gene 1 (URB) & 4 & 0 & $3 q 13.2$ \\
\hline TTATTTTCCT & Hs.363492 & DEAD (Asp-Glu-Ala-Asp) box polypeptide 18 (DDX18) & 4 & 0 & $2 \mathrm{q} 14.1$ \\
\hline AGTCTCCCCT & Hs. 250429 & Suppressor of Ty 6 homolog (S. cerevisiae) (SUPT6H) & 4 & 0 & $17 \mathrm{q} 11.2$ \\
\hline CTGACTTAAA & Hs.104741 & PDZ binding kinase (PBK) & 4 & 0 & $8 \mathrm{p} 21.2$ \\
\hline GGCTAAGGAG & BI017905 & EST & 4 & 0 & \\
\hline TTCCCTGGCC & BU153762 & EST & 4 & 0 & \\
\hline TGGTATTTCG & Hs.355398 & Aldehyde dehydrogenase 16 family, member A1 (MGC10204) & 4 & 0 & $19 q 13.33$ \\
\hline GCACACAGAA & Hs.124186 & Ring finger protein 2 (RNF2) & 4 & 0 & $1 \mathrm{q} 25.3$ \\
\hline TGTCTGGATG & Hs. 149443 & Cytochrome b-561 domain containing 2 (CYB561D2) & 4 & 0 & $3 \mathrm{p} 21.3$ \\
\hline CCAGTGTCCT & AW809533 & EST & 4 & 0 & \\
\hline TGAGTATACC & Hs.115660 & DNA cross-link repair 1B (PSO2 homolog, S. cerevisiae) (DCLRE1B) & 4 & 0 & $1 \mathrm{p} 13.2$ \\
\hline CCCATCGTTC & CD239116 & EST & 4 & 0 & \\
\hline GCCATAAAAT & Hs.1908 & Proteoglycan 1 , secretory granule (PRG1) & 4 & 0 & $10 \mathrm{q} 22.1$ \\
\hline AAGCATTAAA & Hs.550753 & Protein kinase, cAMP-dependent, regulatory, type I, beta (PRKAR1B) & 4 & 0 & 7pter-p22 \\
\hline AGGGATGGCC & Hs.515139 & Transmembrane emp24 domain containing 1 (TMED1) & 4 & 0 & $19 \mathrm{p} 13.2$ \\
\hline
\end{tabular}


Table III supplementary. List of the genes up-regulated in C5.2 vs. HB4a mammary cells.

\begin{tabular}{|c|c|c|c|c|c|}
\hline TAG & UniGene & Description (locus name) & $\mathrm{HB} 4 \mathrm{a}$ & $\mathrm{C} 5.2$ & $\begin{array}{c}\text { Chromosome } \\
\text { region }\end{array}$ \\
\hline
\end{tabular}

CTGTGTTTAG Hs.452583 Transcribed locus, strongly similar to NP_061322.2 matrin 3 (Homo sapiens)

CCAGGAACCT Hs.446352 v-erb-b2 erythroblastic leukemia viral oncogene homolog 2, neuro/glioblastoma derived oncogene homolog (avian) (ERBB2)

GCAGGTTCCC AI624297 EST

TAAGTAAAGT Hs.368260 Hypothetical protein MGC11242 (MGC11242)

CTATTTAGGG Hs.7736 Mitochondrial ribosomal protein L27 (MRPL27)

TCTTCTCCCT Hs.506748 Hepatoma-derived growth factor (high-mobility group protein 1-like) (HDGF)

$\begin{array}{crc}0.00 & 230.52 & 5 \mathrm{q} 31.2 \\ 0.00 & 85.68 & 17 \mathrm{q} 11.2-\mathrm{q} 12 \\ & & \\ 1.00 & 19.38 & \\ 0.00 & 16.32 & 17 \mathrm{q} 21.32 \\ 0.00 & 16.32 & 17 \mathrm{q} 21.3-\mathrm{q} 22 \\ 1.00 & 14.28 & 1 \mathrm{q} 21-\mathrm{q} 23 \\ 2.00 & 25.50 & 5 \mathrm{p} 15.2 \\ 1.00 & 12.24 & 4 \mathrm{q} 11-\mathrm{q} 13 \\ 2.00 & 23.46 & 22 \mathrm{q} 13.1 \\ 1.00 & 11.22 & \\ 1.00 & 11.22 & 19 \mathrm{q} 13.33 \\ 0.00 & 10.20 & 20 \mathrm{q} 13 \\ 1.00 & 10.20 & 19 \mathrm{p} 13.3 \\ 2.00 & 18.36 & 9 \mathrm{q} 22.32 \\ 1.00 & 9.18 & 12 \mathrm{q} 13.3 \\ 1.00 & 9.18 & 2 \mathrm{p} 22.3 \\ 2.00 & 17.34 & 7 \mathrm{q} 31\end{array}$

CCCAGCTAAT Hs.200395 Centromere protein H (CENPH)

TGATTGGTGG Hs.74615 Platelet-derived growth factor receptor, alpha polypeptide (PDGFRA)

GCCCCCAATA Hs.445351 Lectin, galactoside-binding, soluble, 1 (galectin 1) (LGALS1)

TACCATCGAT BI226498 EST

GGCAGAGACC Hs.467133 Nucleoporin 62 kDa (NUP62)

GCTCTGCCTC Hs.252549 Cathepsin Z (CTSZ)

CACGCAATGC Hs.515053 Amino-terminal enhancer of split (AES)

GATTTTGTAG Hs.494604 Acidic (leucine-rich) nuclear phosphoprotein 32 family, member B (ANP32B)

TAGCTTCCTT Hs.44276 Homeo box C10 (HOXC10)

TAAACATTGT Hs.468140 DKFZP564F0522 protein (DKFZP564F0522)

GTAGACACCT Hs.418133 Intracellular membrane-associated calcium-independent phospholipase A2 gamma (IPLA2 GAMMA)

ATGGCAGGAG Hs.194121 RNA terminal phosphate cyclase-like 1 (RCL1)

TAAATACAGT Hs.503043 Carnitine palmitoyltransferase 1A (liver) (CPT1A)

TGTATCACTG BF932124 EST

CATTGTAATA BE871060 EST

CCTAAGGCTA Hs.108371 E2F transcription factor 4, p107/p130-binding (E2F4)

TGGATCAACC Hs.74034 Caveolin 1, caveolae protein, 22 kDa (CAV1)

CAGGAACCTG BE468107 EST

TCACAGCTGT Hs.255935 B-cell translocation gene 1, anti-proliferative (BTG1)

CTACCAGGCC Hs.334848 Hypothetical protein FLJ13291 (FLJ13291)

TCTCAATTCT Hs.467637 Cell division cycle 42 (GTP binding protein, $25 \mathrm{kDa}$ (CDC42)

GCTTTCATTG Hs.2704 Glutathione peroxidase 2 (GPX2)

TTTTGATAAA Hs.388927 YY1 transcription factor (YY1)

TCTGCTAAAG Hs.475685 High-mobility group box 1 (HMGB1)

AAGAGTTGGG Hs.536652 Transcribed locus

TAAGCAGATG Hs.306425 Inhibitor of Bruton agammaglobulinemia tyrosine kinase (IBTK)

GCGAAACCCC Hs.288945 Hypothetical protein FLJ13448 (FLJ13448)

CAGAATAATA Hs.204475 HIV TAT specific factor 1 (HTATSF1)

GATTTGTAGC BE279179 EST

ACCGCCTGTG Hs.79625 Chromosome 20 open reading frame 149 (C20orf149)

TCCTTTGCAA Hs.81892 KIAA0101 (KIAA0101)

CTACATAATA Hs.432385 DEAD (Asp-Glu-Ala-Asp) box polypeptide 7 (DDX7)

CTGCCTCCTT Hs.472847 Chromosome 20 open reading frame 35 (C20orf35)

GCTACAGGTA Hs.349306 Hypothetical protein FLJ31951 (FLJ31951)

TTCAAGAAAC Hs.458974 Transcribed locus

CTCATAAGAA Hs.549495 Transcribed locus, strongly similar to XP_529639.1

TTAGCTTGTT BU074305 EST

CAGGATCCAG Hs.447477 Family with sequence similarity 10, member A5 (FAM10A5)

GCAGATCGGG BF336989 EST

GCGGAGAGAG Hs.546104 Transcribed locus

AGTAGGTGGC Hs.459311 Hypothetical protein DKFZp547K1113 (DKFZp547K1113)

CGAATAAAAT Hs.139896 Macrophage erythroblast attacher (MAEA)

TACAATAAAC Hs.507910 Progesterone receptor membrane component 2 (PGRMC2)

GTTGTGATGT Hs.374477 Ewing sarcoma breakpoint region 1 (EWSR1)

GTTGCAAGTG BQ709743 EST

CTGTTGATGC BG570533 EST

TACAAAACCA Hs.79110 Nucleolin (NCL)

$0.00 \quad 8.16 \quad 9 \mathrm{p} 24.1-\mathrm{p} 23$

$0.00 \quad 8.1611 \mathrm{q} 13.1-\mathrm{q} 13.2$

$0.00 \quad 8.16$

$0.00 \quad 8.16$

$0.00 \quad 8.16$

$0.00 \quad 8.16$

$0.00 \quad 8.16$

$2.00 \quad 16.32$

$1.00 \quad 8.16$

$1.00 \quad 8.16$

$1.00 \quad 8.16$

$1.00 \quad 8.16$

$1.00 \quad 8.16$

$1.00 \quad 8.16$

$1.00 \quad 8.16$

$1.00 \quad 8.16$

1.00

2.00

2.00

0.00

0.00
0.00

0.00

0.00

0.00

0.00

0.00
0.00

0.00

3.00

$2.00 \quad 14.28$

$2.00 \quad 14.28$

$1.00 \quad 7.14$

$1.00 \quad 7.14$

$1.00 \quad 7.14$

$1.00 \quad 7.14$

$1.00 \quad 7.14$ 16q21-q22

$7 \mathrm{q} 31.1$

$12 \mathrm{q} 22$

$16 q 22.1$

$1 \mathrm{p} 36.1$

$14 \mathrm{q} 24.1$

$14 \mathrm{q}$

$13 q 12$

6q14.1

2q33.1

8.16 Xq26.1-q27.2

15.30

$5.30 \quad 20 q 13.33$

$7.14 \quad 15 \mathrm{q} 22.31$

$7.14 \quad 21$

$7.14 \quad 20 q 13.12$

$7.14 \quad 5 q 33.3$

$7.14 \quad 8$

$7.14 \quad 14$

7.14

7.14

7.14

$11 \mathrm{p} 15.1$

$\mathrm{X}$

$15 q 26.1$

$4 \mathrm{p} 16.3$

$4 \mathrm{q} 26$

22q12.2

2q12-qter 
Table III supplementary. Continuted.

\begin{tabular}{llll}
\hline TAG & UniGene & \\
& & & Description (locus name) \\
\hline CGACCCTCTC & Hs.400625 & Glutamate-rich WD repeat containing 1 (GRWD1) \\
TAACCTCAGG & Hs.18166 & KIAA0870 protein (KIAA0870) \\
TGAAGAGAAT & Hs.364260 & Forkhead box R2 (FOXR2) \\
GCCGCCATCA & Hs.212102 & Protein disulfide isomerase-associated 6 (TXNDC7) \\
AAAGGGGGCA & Hs.516539 & Heterogeneous nuclear ribonucleoprotein A3 (HNRPA3) \\
GCTGGGAGGG & Hs.325650 & EH-domain containing 2 (EHD2) \\
GGAATGAGGG & Hs.189810 & Sulfotransferase family 4A, member 1 (SULT4A1) \\
CTCTTCAGGA & Hs.30954 & Phosphomevalonate kinase (PMVK) \\
GGATGGGTGT & Hs.513330 & Chromosome 16 open reading frame 51 (C16orf51) \\
TCAAGAAATT & Hs.152978 & Proteasome (prosome, macropain) activator subunit 3 (PA28 gamma; \\
& & Ki) (PSME3) \\
TACTGCTCGG & Hs.553141 & Transcribed locus \\
GAAAAAATGT & Hs.194329 & Transcription elongation factor A (SII)-like 4 (TCEAL4) \\
CCGATTTTTA & Hs.26570 & Hypothetical protein FLJ20422 (FLJ20422) \\
TGGGAAGGGA & Hs.15961 & Chromosome 9 open reading frame 23 (C9orf23) \\
CTGTTGTTGG & AI275403 & EST \\
CATAGGTTAA & BF348753 & EST \\
GTGGCAGCGC & Hs.348326 & Stathmin-like 3 (STMN3) \\
GTGAAACTCC & Hs.522394 & Heat shock 70 kDa protein 5 (glucose-regulated protein, 78 kDa) (HSPA5) \\
GAGGACGAAG & Hs.50425 & Unactive progesterone receptor, 23 kDa (TEBP) \\
GCAGGTTCCT & Hs.297729 & Transcribed locus \\
ACCACGCCGT & Hs.436329 & Scribbled homolog (Drosophila) (SCRIB) \\
TCCACTACCA & Hs.405692 & CGI-116 protein (CGI-116) \\
TAGTTAAGCC & Hs.458598 & UTP14, U3 small nucleolar ribonucleoprotein, homolog A (yeast) \\
& & (UTP14A) \\
& & Stall
\end{tabular}

TCCATCCCTT Hs.7527 Small fragment nuclease (DKFZP566E144)

CTGGCCGACT Hs.513883 Proline-, glutamic acid-, leucine-rich protein 1 (PELP1)

GAGTCAGCAT Hs.166463 Heterogeneous nuclear ribonucleoprotein U (scaffold attachment factor A) (HNRPU)

CTAAAGACTT

Hs.176247 Dipeptidylpeptidase 10 (DPP10)

CCTGAGCTGG Hs.97910 Hypothetical protein LOC253264 (LOC253264)

GCAGAAGAGG Hs.546465 Leukocyte receptor cluster (LRC) member 9 (LENG9)

CCCGGGGCCT Hs.90691 Nucleophosmin/nucleoplasmin, 3 (NPM3)

GCCTGCTGGG Hs.433951 Glutathione peroxidase 4 (phospholipid hydroperoxidase) (GPX4)

CAGTTTGTAC Hs.530331 Pyruvate dehydrogenase (lipoamide) alpha 1 (PDHA1)

TTTGTAGATG Hs.184233 Heat shock $70 \mathrm{kDa}$ protein 9B (mortalin-2) (HSPA9B)

ACAAGGTGCT BU853523 EST

TAAAATAAGA Hs.69293

GCGCAGACTT Hs.14745

GGAGAAGATG Hs.492516

TTAAGAGGGA Hs.531550

AGACATAAAT CA429050

CACGGACACG Hs.500756

CTGAGCTGTA

Hs. 8737

CCATAAATGT

Hs. 74052

TGAAGCAGTA

Hs. 232543

GAAGGGATCA Hs.501345

TAGCAGAGGC Hs.513266

AAGACAGGGC BE080148

GAGCCTGTAA Hs.406377

TCCGTGGTTG Hs.201641

GGCTGGGGGG AV699465

TTCCCCTTCC

Hs.368376
Hexosaminidase B (beta polypeptide) (HEXB)

Chromosome 10 open reading frame 9 (C10orf9)

Prefoldin 2 (PFDN2)

Transducer of ERBB2, 1 (TOB1)

EST

Glutamic-oxaloacetic transaminase 1, soluble (aspartate amino-

transferase 1) (GOT1)

WD repeat domain 6 (WDR6)

CDNA FLJ40823 fis, clone TRACH2011093

Programmed cell death 4 (neoplastic transformation inhibitor) (PDCD4)

C-terminal binding protein 2 (CTBP2)

NADH dehydrogenase (ubiquinone) 1 beta subcomplex, 10, $22 \mathrm{kDa}$ (NDUFB10)

EST

Hypothetical protein DKFZp762N1910 (DKFZp762N1910)

Brain abundant, membrane attached signal protein 1 (BASP1)

EST

Signal recognition particle receptor ('docking protein') (SRPR)
HB4a C5.2 Chromosome region

$\begin{array}{lcc}1.00 & 7.14 & 19 \mathrm{q} 13.32 \\ 1.00 & 7.14 & 8 \mathrm{q} 24.3 \\ 1.00 & 7.14 & \mathrm{Xp} 11.22 \\ 1.00 & 7.14 & 2 \mathrm{p} 25.1 \\ 1.00 & 7.14 & 2 \mathrm{q} 31.2 \\ 1.00 & 7.14 & 19 \mathrm{q} 13.3 \\ 1.00 & 7.14 & 22 \mathrm{q} 13.2-\mathrm{q} 13.31 \\ 1.00 & 7.14 & 1 \mathrm{p} 13-\mathrm{q} 23 \\ 1.00 & 7.14 & 16 \mathrm{p} 13.13-\mathrm{p} 12.3 \\ 2.00 & 13.26 & 17 \mathrm{q} 21 \\ & & \\ 2.00 & 13.26 & 7 \\ 2.00 & 13.26 & \mathrm{Xq} 22.2 \\ 0.00 & 6.12 & 19 \mathrm{p} 13.11 \\ 0.00 & 6.12 & 9 \mathrm{p} 13.3 \\ 0.00 & 6.12 & \\ 0.00 & 6.12 & \\ 0.00 & 6.12 & 20 \mathrm{q} 13.3 \\ 0.00 & 6.12 & 9 \mathrm{q} 33-\mathrm{q} 34.1 \\ 0.00 & 6.12 & 12 \mathrm{q} 13.3 \\ 0.00 & 6.12 & 15 \\ 0.00 & 6.12 & 8 \mathrm{q} 24.3 \\ 0.00 & 6.12 & 12 \mathrm{q} 23.3 \\ 0.00 & 6.12 & \mathrm{Xq} 25\end{array}$

$\begin{array}{lll}0.00 & 6.12 \quad 11 \mathrm{q} 23.1-\mathrm{q} 23.2\end{array}$

$\begin{array}{lll}0.00 & 6.12 & 17 \mathrm{p} 13.2\end{array}$

$0.00 \quad 6.12 \quad 1 q 44$

$0.00 \quad 6.12 \quad 2 q 14.1$

$\begin{array}{lll}0.00 & 6.12 & 10 \mathrm{q} 22.2\end{array}$

$\begin{array}{lll}0.00 & 6.12 & 19 \mathrm{q} 13.4\end{array}$

$\begin{array}{lll}0.00 & 6.12 & 10 \mathrm{q} 24.31\end{array}$

$\begin{array}{lll}2.00 & 12.24 & 19 \mathrm{p} 13.3\end{array}$

$\begin{array}{lll}2.00 & 12.24 \quad \mathrm{Xp} 22.2-\mathrm{p} 22.1\end{array}$

$2.00 \quad 12.24 \quad 5 \mathrm{q} 31.1$

$2.00 \quad 12.24$

$2.00 \quad 12.24$

$1.00 \quad 6.12$

$1.00 \quad 6.12$

$1.00 \quad 6.12$

$1.00 \quad 6.12$

$1.00 \quad 6.12$

$1.00 \quad 6.12$

$1.00 \quad 6.12$

$1.00 \quad 6.12$

$1.00 \quad 6.12$

$1.00 \quad 6.12$

$5 \mathrm{q} 13$

10p11.21

1q23.3

$17 \mathrm{q} 21$

10q24.1-q25.1

$3 \mathrm{p} 21.31$

10q24

10q26.13

$16 \mathrm{p} 13.3$

$1.00 \quad 6.12$

$1.00 \quad 6.12$

$1.00 \quad 6.12$

$1.00 \quad 6.12$

$1.00 \quad 6.12$ 11q12.3

5p15.1-p14

$11 \mathrm{q} 24.3$ 
Table III supplementary. Continuted.

\begin{tabular}{|c|c|c|c|c|c|}
\hline TAG & UniGene & Description (locus name) & HB4a & $\mathrm{C} 5.2$ & $\begin{array}{l}\text { Chromosome } \\
\text { region }\end{array}$ \\
\hline GCGCAGAGGT & Hs.356799 & cDNA clone IMAGE:6726542, partial cds & 12.00 & 68.34 & \\
\hline TGGCTGGGAA & Hs. 534373 & Vesicle-associated membrane protein 8 (endobrevin) (VAMP8) & 2.00 & 11.22 & 2p12-p11.2 \\
\hline СТTAАТССТG & Hs. 221847 & Solute carrier family 38, member 2 (SLC38A2) & 2.00 & 11.22 & $12 \mathrm{q}$ \\
\hline GTGTGTGTGT & Hs. 2549 & Adrenergic, beta-3-, receptor (ADRB3) & 0.00 & 5.10 & 8p12-p11.2 \\
\hline CCAGGAACCC & BQ898423 & EST & 0.00 & 5.10 & \\
\hline TTGTAAGAAC & Hs. 513280 & Transcribed locus & 0.00 & 5.10 & 16 \\
\hline CCTCTAGTCC & Hs. 488778 & cDNA FLJ26938 fis, clone RCT07169 & 0.00 & 5.10 & 7 \\
\hline TGATTTCACC & UV723019 & EST & 0.00 & 5.10 & \\
\hline AGGTTTCCTC & Hs. 12970 & Proteasome (prosome, macropain) 26S subunit, non-ATPase, 3 (PSMD3) & 0.00 & 5.10 & $17 \mathrm{q} 21.1$ \\
\hline TCTTCTCСТG & Hs. 128553 & Wingless-type MMTV integration site family member 2 (WNT2) & 0.00 & 5.10 & $7 \mathrm{q} 31$ \\
\hline GAGCTGTGGT & Hs.282931 & Solute carrier family 17 (sodium phosphate), member 4 (SLC17A4) & 0.00 & 5.10 & $6 \mathrm{p} 22-\mathrm{p} 21.3$ \\
\hline TGCAGAGTAA & Hs. 512065 & Similar to cytochrome c oxidase (LOC285849) & 0.00 & 5.10 & \\
\hline TGGGGTTCCA & BE962013 & EST & 0.00 & 5.10 & \\
\hline TCCACTGGCC & Hs. 441783 & Chromosome 14 open reading frame 78 (C14orf78) & 0.00 & 5.10 & $14 q 32.33$ \\
\hline GTCACCCCCA & Hs.10082 & $\begin{array}{l}\text { Potassium intermediate/small conductance calcium-activated channel, } \\
\text { subfamily N, member } 4 \text { (KCNN4) }\end{array}$ & 0.00 & 5.10 & $19 \mathrm{q} 13.2$ \\
\hline CACTGTGTGT & Hs.532987 & Chromosome 18 open reading frame 22 (C18orf22) & 0.00 & 5.10 & $18 \mathrm{q} 23$ \\
\hline GTGAAACTGC & Hs.405942 & Hypothetical protein LOC339229 (LOC339229) & 0.00 & 5.10 & $17 \mathrm{q} 25.3$ \\
\hline GAGGATTTGG & Hs.370102 & Chromosome 10 open reading frame $70(\mathrm{C} 10$ orf 70$)$ & 0.00 & 5.10 & $10 \mathrm{q} 21.1$ \\
\hline ТСТTТССССА & Hs. 268557 & Pleckstrin homology-like domain, family A, member 3 (PHLDA3) & 0.00 & 5.10 & $1 \mathrm{q} 31$ \\
\hline GGGCCCTTGG & Hs. 525610 & Chromosome 14 open reading frame $172(\mathrm{C} 14$ orf 172$)$ & 0.00 & 5.10 & $14 q 32.32$ \\
\hline TATCTGTCTA & Hs. 436687 & SET translocation (myeloid leukemia-associated) (SET) & 10.00 & 51.00 & $9 \mathrm{q} 34$ \\
\hline CAAGATAAAT & Hs.5258 & Melanoma antigen family D, 1 (MAGED1) & 2.00 & 10.20 & $\mathrm{Xp} 11.23$ \\
\hline TACCATCAAG & Hs.515955 & $\begin{array}{l}\text { Similar to cysteine and histidine-rich domain (CHORD)-containing, zinc- } \\
\text { binding protein } 1\end{array}$ & 2.00 & 10.20 & $2 \mathrm{p} 21$ \\
\hline GACAGCTGAG & Hs. 175473 & Adenylate kinase 1 (AK1) & 2.00 & 10.20 & $9 \mathrm{q} 34.1$ \\
\hline TGTGAACAAC & Hs. 534331 & Nudix (nucleoside diphosphate linked moiety X)-type motif 1 (NUDT1) & 2.00 & 10.20 & $7 \mathrm{p} 22$ \\
\hline GCAAAAAAAA & Hs.284491 & Pyridoxal (pyridoxine, vitamin B6) kinase (PDXK) & 2.00 & 10.20 & $21 \mathrm{q} 22.3$ \\
\hline TTAAGGGATG & Hs.521008 & Tumor necrosis factor, alpha-induced protein 9 (TNFAIP9) & 2.00 & 10.20 & $7 \mathrm{q} 21.12$ \\
\hline GAAGCTTTGC & Hs. .523560 & Heat shock $90 \mathrm{kDa}$ protein 1, alpha (HSPCA) & 1.00 & 5.10 & $14 q 32.33$ \\
\hline GGCTGGTCCC & Hs.380801 & Pecanex-like 3 (Drosophila) (PCNXL3) & 1.00 & 5.10 & $11 \mathrm{q} 13.1$ \\
\hline CATAACCTTC & Hs. 405144 & Splicing factor, arginine/serine-rich 3 (SFRS3) & 1.00 & 5.10 & $6 \mathrm{p} 21$ \\
\hline GTGGAATAAA & Hs. 512776 & Latent transforming growth factor beta binding protein 2 (LTBP2) & 1.00 & 5.10 & $14 q 24$ \\
\hline CCCCCGGCTA & Hs. 144722 & cDNA FLJ43899 fis, clone TESTI4009928 & 1.00 & 5.10 & 9 \\
\hline GGTGAGACCT & Hs. 433863 & Prostatic binding protein (PBP) & 1.00 & 5.10 & $12 \mathrm{q} 24.23$ \\
\hline GATTCATAAA & Hs. 372688 & Rho-related BTB domain containing 2 (RHOBTB2) & 1.00 & 5.10 & $8 \mathrm{p} 21.3$ \\
\hline CTGGTAATAA & AI524746 & EST & 1.00 & 5.10 & \\
\hline GTTCGGGCCG & Hs.502914 & Dipeptidylpeptidase 3 (DPP3) & 1.00 & 5.10 & $11 q 12-q 13.1$ \\
\hline AGGAACTGTA & Hs. 495473 & Notch homolog 1, translocation-associated (Drosophila) (NOTCH1) & 1.00 & 5.10 & $9 \mathrm{q} 34.3$ \\
\hline GTGTCGGGGG & Hs.459795 & Leucine zipper domain protein (FLJ22386) & 1.00 & 5.10 & $16 \mathrm{p} 13.3$ \\
\hline CACATCTCTG & Hs.355606 & Hypothetical protein MGC23909 (MGC23909) & 1.00 & 5.10 & $5 q 14.2$ \\
\hline TATATATATC & Hs.414407 & Kinetochore associated 2 (KNTC2) & 1.00 & 5.10 & $18 \mathrm{p} 11.32$ \\
\hline TACCGCCCGT & Hs.238513 & Chromosome 7 open reading frame 21 (C7orf21) & 1.00 & 5.10 & $7 \mathrm{q} 36.1$ \\
\hline GGAAACTGAT & Hs.83916 & $\begin{array}{l}\text { NADH dehydrogenase (ubiquinone) } 1 \text { alpha subcomplex, 5, } 13 \mathrm{kDa} \\
\text { (NDUFA5) }\end{array}$ & 1.00 & 5.10 & $7 \mathrm{q} 32$ \\
\hline AGTGCTCACT & Hs.540696 & $\begin{array}{l}\text { Solute carrier family } 6 \text { (neurotransmitter transporter, creatine), member } 8 \\
\text { (SLC6A8) }\end{array}$ & 1.00 & 5.10 & $\mathrm{Xq} 28$ \\
\hline AATAAATTCC & Hs.439671 & Neuroblastoma, suppression of tumorigenicity 1 (NBL1) & 1.00 & 5.10 & $1 \mathrm{p} 36.13-\mathrm{p} 36.11$ \\
\hline CTTCGAAACT & Hs. 464572 & NADH dehydrogenase (ubiquinone) flavoprotein 2, 24 kDa (NDUFV2) & 1.00 & 5.10 & 18p11.31-p11.2 \\
\hline TAAACCTGTC & Hs.435610 & WW domain containing adaptor with coiled-coil (WAC) & 1.00 & 5.10 & 10 \\
\hline CCGATCACCG & Hs. 429180 & Eukaryotic translation initiation factor 2, subunit 2 beta, 38 kDa (EIF2S2) & 1.00 & 5.10 & 20pter-q12 \\
\hline TTCCCAAGGC & Hs. 437846 & Smoothened homolog (Drosophila) (SMO) & 1.00 & 5.10 & $7 q 32.3$ \\
\hline CAGCTTGCAA & Hs. 105465 & Small nuclear ribonucleoprotein polypeptide F (SNRPF) & 1.00 & 5.10 & $12 \mathrm{q} 23.1$ \\
\hline GGTGTGTCCG & Hs.386939 & Ubiquitin specific protease 7 (herpes virus-associated) (USP7) & 1.00 & 5.10 & $16 \mathrm{p} 13.3$ \\
\hline GAGTGGCTAT & Hs.299055 & GDP dissociation inhibitor 2 (GDI2) & 1.00 & 5.10 & $10 \mathrm{p} 15$ \\
\hline
\end{tabular}


Table III supplementary. Continuted.

\begin{tabular}{|c|c|c|c|c|c|}
\hline TAG & UniGene & Description (locus name) & HB4a & $\mathrm{C} 5.2$ & $\begin{array}{l}\text { Chromosome } \\
\text { region }\end{array}$ \\
\hline TGCCCAGCAA & Hs. 235116 & G protein-coupled receptor kinase 6 (GRK6) & 1.00 & 5.10 & $5 q 35$ \\
\hline CCCTTGACCC & Hs.79769 & Protocadherin 1 (cadherin-like 1) (PCDH1) & 1.00 & 5.10 & $5 q 32-q 33$ \\
\hline TTGTTCTTTG & Hs. 483408 & $\begin{array}{l}\text { Protein phosphatase } 2 \text { (formerly } 2 \mathrm{~A} \text { ), catalytic subunit, alpha isoform } \\
\text { (PPP2CA) }\end{array}$ & 1.00 & 5.10 & $5 q 31.1$ \\
\hline CTTGAGTCAC & Hs. 214043 & Chromosome 6 open reading frame 79 (C6orf79) & 1.00 & 5.10 & $6 \mathrm{p} 24.3-\mathrm{p} 23$ \\
\hline TGGGCAAACC & BE967503 & EST & 1.00 & 5.10 & \\
\hline GGAGCACTGT & Hs. 528952 & Tripartite motif-containing 25 (TRIM25) & 1.00 & 5.10 & $17 \mathrm{q} 23.1$ \\
\hline AGTGGAGGTG & Hs.499891 & Heterogeneous nuclear ribonucleoprotein H3 (2H9) (HNRPH3) & 1.00 & 5.10 & $10 \mathrm{q} 22$ \\
\hline CAGTATCCCA & Hs. 474978 & Transducer of ERBB2, 2 (TOB2) & 1.00 & 5.10 & $22 \mathrm{q} 13.2-\mathrm{q} 13.31$ \\
\hline TATTTATTCA & Hs.490795 & $\begin{array}{l}\text { Family with sequence similarity } 62 \text { (C2 domain containing) member B } \\
\text { (CHR2SYT) }\end{array}$ & 1.00 & 5.10 & $7 \mathrm{q} 36.3$ \\
\hline GATGAGTGGA & Hs.744 & Ferredoxin 1 (FDX1) & 1.00 & 5.10 & $11 \mathrm{q} 22$ \\
\hline GGAGCGTGGG & BE538756 & EST & 1.00 & 5.10 & \\
\hline GCATTTAAAA & Hs.552946 & Homo sapiens, clone IMAGE:4045462, mRNA & 1.00 & 5.10 & 15 \\
\hline GTGCTGGTGC & Hs.9613 & Angiopoietin-like 4 (ANGPTL4) & 1.00 & 5.10 & $19 \mathrm{p} 13.3$ \\
\hline AGCCTGACTG & Hs.289108 & Family with sequence similarity 3 , member A (FAM3A) & 1.00 & 5.10 & $\mathrm{Xq} 28$ \\
\hline GAGCGCAGCG & Hs.493202 & Cleavage and polyadenylation specific factor $1,160 \mathrm{kDa}$ (CPSF1) & 1.00 & 5.10 & $8 \mathrm{q} 24.23$ \\
\hline TAGGACAACT & Hs. 511034 & $\begin{array}{l}\text { Transcribed locus, weakly similar to XP_574882.1 PREDICTED: } \\
\text { similar to H3 histone, family 3B (Rattus norvegicus) }\end{array}$ & 1.00 & 5.10 & \\
\hline GTAGTTACTG & AA581135 & EST & 1.00 & 5.10 & \\
\hline GAGGGACTCC & Hs.75238 & Chromatin assembly factor 1 , subunit B (p60) (CHAF1B) & 1.00 & 5.10 & $21 \mathrm{q} 22.13$ \\
\hline CTAGCCAGCA & Hs. 501420 & Nicalin homolog (zebrafish) (NCLN) & 1.00 & 5.10 & $19 \mathrm{p} 13.3$ \\
\hline TTGTTCTGCT & Hs. 458358 & TSPY-like 1 (TSPYL1) & 1.00 & 5.10 & $6 q 22-q 23$ \\
\hline CTGCATAGAT & Hs. 494529 & Fanconi anemia, complementation group C (FANCC) & 1.00 & 5.10 & $9 q 22.3$ \\
\hline GTGTGAGTGT & Hs. 490347 & Makorin, ring finger protein, 1 (MKRN1) & 1.00 & 5.10 & $7 \mathrm{q} 34$ \\
\hline TCAGCCGCTA & Hs. 434213 & Chromosome 9 open reading frame 89 (C9orf89) & 1.00 & 5.10 & $9 \mathrm{q} 22.31$ \\
\hline GGAATATGCA & Hs. 224764 & Chromosome 20 open reading frame 155 (C20orf155) & 1.00 & 5.10 & 20p13-p12.3 \\
\hline ATTCAGCACC & Hs.11125 & Signal peptidase complex subunit 1 homolog (S. cerevisiae) (SPCS1) & 1.00 & 5.10 & $3 \mathrm{p} 21.1$ \\
\hline AAGTACGAGG & Hs.445081 & NS5ATP13TP2 protein (NS5ATP13TP2) & 1.00 & 5.10 & $11 \mathrm{q} 23.3$ \\
\hline GCAGACCCAC & Hs.15277 & Chromosome 16 open reading frame 33 (C16orf33) & 3 & 14.3 & $16 \mathrm{p} 13.3$ \\
\hline TAAACTGTTT & Hs.291219 & cDNA FLJ37429 fis, clone BRAWH2001666 & 15 & 69.4 & 19 \\
\hline CCAACGTGTA & AI272324 & EST & 2 & 9.18 & \\
\hline CCACACAAGC & Hs. 484363 & Ring finger protein 130 (RNF130) & 2 & 9.18 & $5 q 35.3$ \\
\hline GCCAAGAATC & Hs. 503047 & Mitochondrial ribosomal protein L21 (MRPL21) & 2 & 9.18 & $11 \mathrm{q} 13.3$ \\
\hline GAGTCGTAAT & Hs.370292 & BRCA2 and CDKN1A interacting protein (BCCIP) & 2 & 9.18 & $10 \mathrm{q} 26.1$ \\
\hline TGGATCCTCG & Hs.5268 & Zinc finger, DHHC-type containing 4 (ZDHHC4) & 3 & 13.3 & $7 \mathrm{p} 22.1$ \\
\hline CCCAAGCTAG & Hs.520973 & Heat shock $27 \mathrm{kDa}$ protein 1 (HSPB1) & 7 & 29.6 & $7 q 11.23$ \\
\hline GCTCTGTTCA & Hs.18192 & Serine/arginine repetitive matrix 1 (SRRM1) & 0 & 4.08 & $1 \mathrm{p} 36.11$ \\
\hline AAGGTGGAGT & Hs.9573 & ATP-binding cassette, sub-family F (GCN20), member 1 (ABCF1) & 0 & 4.08 & $6 \mathrm{p} 21.33$ \\
\hline TGTCATCACA & Hs.116479 & Lysyl oxidase-like 2 (LOXL2) & 0 & 4.08 & $8 \mathrm{p} 21.3-\mathrm{p} 21.2$ \\
\hline TAAGCCATAT & Hs.43818 & Hypothetical protein LOC221710 (LOC221710) & 0 & 4.08 & $6 \mathrm{p} 24.1$ \\
\hline GTAAATGAGC & Hs. 247324 & Mitochondrial ribosomal protein S14 (MRPS14) & 0 & 4.08 & $1 q 23-1 q 25$ \\
\hline TAAAAAGAGA & Hs.11108 & Cdk5 and Abl enzyme substrate 1 (CABLES1) & 0 & 4.08 & $18 \mathrm{q} 11.2$ \\
\hline GGCTATACAG & Hs. 531111 & YLP motif containing 1 (YLPM1) & 0 & 4.08 & $14 \mathrm{q} 24.3$ \\
\hline TTTGGGCCTA & Hs.70327 & Cysteine-rich protein 1 (intestinal) (CRIP1) & 0 & 4.08 & $14 q 32.33$ \\
\hline CAGCCTGTCG & Hs.26890 & Cat eye syndrome chromosome region, candidate 5 (CECR5) & 0 & 4.08 & 22 \\
\hline GTGATCTTCT & BE926316 & EST & 0 & 4.08 & \\
\hline TTGCCGGTTT & Hs. 471917 & Proteasome (prosome, macropain) inhibitor subunit 1 (PI31) (PSMF1) & 0 & 4.08 & $20 \mathrm{p} 13$ \\
\hline GAGGAAAGCT & Hs. 145726 & BCL2/adenovirus E1B $19 \mathrm{kDa}$ interacting protein 1 (BNIP1) & 0 & 4.08 & $5 q 33-q 34$ \\
\hline TGGAGACTGG & Hs.550499 & Dynamin 1-like (DNM1L) & 0 & 4.08 & $12 \mathrm{p} 11.21$ \\
\hline TATGTAATAT & Hs.435122 & Phosphatidic acid phosphatase type 2A (PPAP2A) & 0 & 4.08 & $5 q 11$ \\
\hline TTAGCACTTC & Hs.488591 & Williams-Beuren syndrome chromosome region 17 (WBSCR17) & 0 & 4.08 & $7 q 11.23$ \\
\hline TTGGTCCTCC & BX393351 & EST & 0 & 4.08 & \\
\hline TAAATCTACA & Hs.288981 & Nucleotide binding protein-like (NUBPL) & 0 & 4.08 & $14 \mathrm{q} 12$ \\
\hline GGATTGGCTG & Hs. 549560 & cDNA FLJ30538 fis, clone BRAWH2001238 & 0 & 4.08 & 19 \\
\hline CTGACCGGTG & Hs. 505806 & Pre-B-cell leukemia transcription factor interacting protein 1 (PBXIP1) & 0 & 4.08 & $1 \mathrm{q} 22$ \\
\hline
\end{tabular}


Table III supplementary. Continuted.

\begin{tabular}{|c|c|c|c|c|c|}
\hline TAG & UniGene & Description (locus name) & HB4a & C5.2 & $\begin{array}{l}\text { Chromosome } \\
\text { region }\end{array}$ \\
\hline TTGTGATGTA & Hs.187199 & $\begin{array}{l}\text { Metastasis associated lung adenocarcinoma transcript } 1 \text { (non-coding RNA) } \\
\text { (MALAT1) }\end{array}$ & 0 & 4.08 & $11 \mathrm{q} 13.1$ \\
\hline TGCTGGAGAA & Hs. 120573 & Hypothetical protein DKFZp434K1172 (DKFZP434K1172) & 0 & 4.08 & $13 q 14.3$ \\
\hline AGCCGTGTAT & Hs.493771 & Chromosome 9 open reading frame 25 (C9orf25) & 0 & 4.08 & $9 \mathrm{p} 13.3$ \\
\hline TATAAAGGGT & Hs.25956 & Sclerostin domain containing 1 (SOSTDC1) & 0 & 4.08 & $7 \mathrm{p} 21.1$ \\
\hline TGACCTCCAG & Hs.494705 & KIAA0859 (KIAA0859) & 0 & 4.08 & $1 \mathrm{q} 24-\mathrm{q} 25.3$ \\
\hline GTCCAACAAC & CB857419 & EST & 0 & 4.08 & \\
\hline TGACTGTGCT & Hs. 524116 & Neurogranin (protein kinase C substrate, RC3) (NRGN) & 0 & 4.08 & $11 \mathrm{q} 24$ \\
\hline TATGAACTGA & Hs. 177766 & Poly(ADP-ribose) polymerase family, member 1 (PARP1) & 0 & 4.08 & $1 q 41-q 42$ \\
\hline GTTGTGGAGG & Hs.73853 & Bone morphogenetic protein 2 (BMP2) & 0 & 4.08 & $20 \mathrm{p} 12$ \\
\hline ACAAGCATAT & Hs.10056 & Cytosolic sialic acid 9-O-acetylesterase homolog (CSE-C) & 0 & 4.08 & $11 \mathrm{q} 24$ \\
\hline ACACTCAATA & CA417269 & EST & 0 & 4.08 & \\
\hline AGAATCACTT & Hs.192127 & Hypothetical protein MGC32020 (MGC32020) & 0 & 4.08 & $19 q 13.11$ \\
\hline TTGGCTTTTC & Hs. 550788 & $\mathrm{AB} 14$ precursor RNA & 0 & 4.08 & 1 \\
\hline TAAAATATAT & Hs.22109 & Bromo adjacent homology domain containing 1 (BAHD1) & 0 & 4.08 & $15 q 15.1$ \\
\hline GTGGATTCAT & Hs.293736 & Activity-dependent neuroprotector (ADNP) & 0 & 4.08 & $20 q 13.13$ \\
\hline GTGGCGTGTG & Hs. 551542 & Prenylcysteine oxidase 1 (PCYOX1) & 0 & 4.08 & $2 \mathrm{p} 13.3$ \\
\hline TGCCTTAGTA & Hs.499000 & DnaJ (Hsp40) homolog, subfamily C, member 1 (DNAJC1) & 0 & 4.08 & $10 \mathrm{p} 12.31$ \\
\hline TGTCACACAC & Hs.20879 & Zinc finger protein 691 (LOC51058) & 0 & 4.08 & $1 \mathrm{p} 34.2$ \\
\hline CCGGGGAGCA & Hs.27059 & GDP-mannose pyrophosphorylase A (GMPPA) & 0 & 4.08 & $2 \mathrm{q} 35$ \\
\hline AATCGCTAAT & Hs.59486 & Hydroxysteroid dehydrogenase like 2 (HSDL2) & 0 & 4.08 & $9 q 32$ \\
\hline CGTTTAATGT & BU933772 & EST & 0 & 4.08 & \\
\hline TGTGTGTGTG & Hs. 330741 & Zinc finger protein 670 (MGC12466) & 0 & 4.08 & $1 \mathrm{q} 44$ \\
\hline GGCGGGGGCG & BQ227822 & EST & 0 & 4.08 & \\
\hline ACTTATTATG & Hs. 156316 & Decorin $(\mathrm{DCN})$ & 0 & 4.08 & $12 \mathrm{q} 13.2$ \\
\hline GCACCTAGTG & Hs. 485041 & Tripartite motif-containing 26 (TRIM26) & 0 & 4.08 & $6 \mathrm{p} 21.3$ \\
\hline GGGAACGCAG & Hs. 438454 & F-box protein 25 (FBX025) & 0 & 4.08 & $8 \mathrm{p} 23.3$ \\
\hline CATACTTTTA & Hs.24643 & Hypothetical protein FLJ31413 (FLJ31413) & 0 & 4.08 & $7 \mathrm{q} 36.1$ \\
\hline AGCAAGCCCC & Hs. 222510 & DAZ associated protein 1 (DAZAP1) & 0 & 4.08 & $19 \mathrm{p} 13.3$ \\
\hline TGTAGGTATT & Hs.497741 & Centromere protein F, 350/400 kDa (mitosin) (CENPF) & 0 & 4.08 & $1 q 32-q 41$ \\
\hline CACCATCAAA & Hs. 268488 & Leucine rich repeat containing 47 (KIAA1185) & 0 & 4.08 & $1 \mathrm{p} 36.32$ \\
\hline GTGGTGGCAG & Hs. 546325 & G protein-coupled receptor, family $\mathrm{C}$, group 5 , member A (GPCR5A) & 0 & 4.08 & $12 \mathrm{p} 13-\mathrm{p} 12.3$ \\
\hline AAACTCGGGT & AW992502 & EST & 0 & 4.08 & \\
\hline TATAAGGTGG & Hs. 223141 & DEAD (Asp-Glu-Ala-Asp) box polypeptide 21 (DDX21) & 0 & 4.08 & $10 \mathrm{q} 21$ \\
\hline AGCTTGCGCT & Hs.193832 & G patch domain containing 4 (GPATC4) & 0 & 4.08 & $1 \mathrm{q} 22$ \\
\hline TGGAGAGCAA & AI301461 & EST & 0 & 4.08 & \\
\hline GCTTTACTTG & BX490890 & EST & 0 & 4.08 & \\
\hline AATGCTGGCA & Hs. 490745 & DnaJ (Hsp40) homolog, subfamily B, member 6 (DNAJB6) & 0 & 4.08 & $7 \mathrm{q} 36.3$ \\
\hline AGGATGTGGC & Hs. 546308 & $\begin{array}{l}\text { TEA domain family member } 1 \text { (SV40 transcriptional enhancer factor) } \\
\text { (TEAD1) }\end{array}$ & 0 & 4.08 & $11 \mathrm{p} 15.4$ \\
\hline CAAATAAACT & Hs.462956 & PPAR binding protein (PPARBP) & 0 & 4.08 & $17 q 12-q 21.1$ \\
\hline TTGCACTTAA & Hs. 175414 & Uncharacterized hypothalamus protein HT008 (HT008) & 0 & 4.08 & $17 \mathrm{q} 23.3$ \\
\hline ACAGCCTGCA & Hs. 153752 & Cell division cycle 25B (CDC25B) & 0 & 4.08 & $20 \mathrm{p} 13$ \\
\hline CCCCGTATGG & Hs.111801 & Arsenate resistance protein ARS2 (ARS2) & 0 & 4.08 & $7 \mathrm{q} 21$ \\
\hline TGTTTTTATG & Hs.3192 & $\begin{array}{l}\text { 6-pyruvoyl-tetrahydropterin synthase/dimerization cofactor of hepatocyte } \\
\text { nuclear factor } 1 \text { alpha (TCF1) (PCBD) }\end{array}$ & 4 & 16.3 & $10 \mathrm{q} 22$ \\
\hline CTTCCTGTAC & Hs. 488861 & Uroplakin 3B (UPK3B) & 4 & 16.3 & $7 \mathrm{q} 11.2$ \\
\hline CGGCTCAAGT & Hs. 515500 & SUMO-1 activating enzyme subunit 1 (SAE1) & 2 & 8.16 & $19 \mathrm{q} 13.32$ \\
\hline CTTAAGGATT & Hs. 530412 & PAI-1 mRNA binding protein (PAI-RBP1) & 2 & 8.16 & $1 \mathrm{p} 31-\mathrm{p} 22$ \\
\hline CAGCTGGGGC & Hs. 172550 & Polypyrimidine tract binding protein 1 (PTBP1) & 2 & 8.16 & $19 \mathrm{p} 13.3$ \\
\hline GACTCTCTCA & Hs. 472667 & Catenin, beta like 1 (CTNNBL1) & 2 & 8.16 & $20 q 11.23-q 12$ \\
\hline ACTCGAATAT & Hs. 546296 & Secreted and transmembrane 1 (SECTM1) & 2 & 8.16 & $17 \mathrm{q} 25$ \\
\hline GCAGGAGAAG & Hs. 528574 & Topoisomerase (DNA) I, mitochondrial (TOP1MT) & 2 & 8.16 & $8 \mathrm{q} 24.3$ \\
\hline TTACTTCCCC & Hs. 502745 & Fatty acid desaturase 2 (FADS2) & 2 & 8.16 & $11 q 12-q 13.1$ \\
\hline GTGAAACCGT & Hs. 533772 & Meteorin, glial cell differentiation regulator (METRN) & 2 & 8.16 & $16 \mathrm{p} 13.3$ \\
\hline TGATGTCTGG & Hs. 517155 & Transmembrane, prostate androgen induced RNA (TMEPAI) & 2 & 8.16 & 20q13.31-q13.33 \\
\hline
\end{tabular}


Table III supplementary. Continuted.

\begin{tabular}{|c|c|c|c|c|c|}
\hline TAG & UniGene & Description (locus name) & $\mathrm{HB} 4 \mathrm{a}$ & C5.2 & $\begin{array}{l}\text { Chromosome } \\
\text { region }\end{array}$ \\
\hline GGAAGTCCTG & Hs.369397 & Transforming growth factor, beta-induced, $68 \mathrm{kDa}$ (TGFBI) & 2 & 8.16 & $5 q 31$ \\
\hline ATTCTTCGGA & Hs. 122363 & WIPI49-like protein 2 (WIPI-2) & 1 & 4.08 & $7 \mathrm{p} 22.1$ \\
\hline ATTGTATGAC & Hs.377001 & mRNA; cDNA DKFZp762L214 (from clone DKFZp762L214) & 1 & 4.08 & 16 \\
\hline CAAATAAACC & Hs.495728 & Pirin (iron-binding nuclear protein) (PIR) & 1 & 4.08 & $\mathrm{Xp} 22.2$ \\
\hline TTTATTTCTA & Hs.349656 & Scavenger receptor class B, member 2 (SCARB2) & 1 & 4.08 & $4 \mathrm{q} 21.1$ \\
\hline GCCCTTCCTG & Hs.520955 & Williams-Beuren syndrome chromosome region 16 (WBSCR16) & 1 & 4.08 & $7 q 11.23$ \\
\hline AATGAGTTTG & Hs.492555 & Enhancer of yellow 2 homolog (Drosophila) $[\mathrm{e}(\mathrm{y}) 2]$ & 1 & 4.08 & $8 \mathrm{q} 23.1$ \\
\hline CACTACACGG & Hs.227729 & FK506 binding protein $2,13 \mathrm{kDa}(\mathrm{FKBP} 2)$ & 1 & 4.08 & $11 \mathrm{q} 13.1-\mathrm{q} 13.3$ \\
\hline GTTCAGAACT & Hs.524969 & Ubiquitin-fold modifier 1 (Ufm1) & 1 & 4.08 & $13 q 13.3$ \\
\hline GTTGAAACCC & Hs. 149425 & $\begin{array}{l}\text { Solute carrier family } 28 \text { (sodium-coupled nucleoside transporter), } \\
\text { member } 3 \text { (SLC8A3) }\end{array}$ & 1 & 4.08 & $9 \mathrm{q} 22.2$ \\
\hline CAGATTTGCA & Hs. 510328 & DEAD (Asp-Glu-Ala-Asp) box polypeptide 24 (DDX24) & 1 & 4.08 & $14 q 32$ \\
\hline GGCACGTGGT & BU928325 & EST & 1 & 4.08 & \\
\hline CCACTCTGGC & Hs.516119 & Glucosidase I (GCS1) & 1 & 4.08 & 2p13-p12 \\
\hline TGTACCTAAC & Hs. 533770 & Solute carrier family 38 , member 1 (SLC38A1) & 1 & 4.08 & $12 q 13.11$ \\
\hline AGCTCTATGA & Hs.531330 & COBW domain containing 2 (CBWD1) & 1 & 4.08 & $9 \mathrm{p} 24.3$ \\
\hline GAGGGACCCA & Hs.447531 & Mesoderm posterior 1 (MESP1) & 1 & 4.08 & $15 \mathrm{q} 26.1$ \\
\hline TATAAAATGG & Hs. 459538 & Aldehyde dehydrogenase 1 family, member A3 (ALDH1A3) & 1 & 4.08 & $15 \mathrm{q} 26.3$ \\
\hline GGGGACTGGT & Hs.282982 & Solute carrier family 25 (mitochondrial carrier), member 18 (SLC25A18) & 1 & 4.08 & $22 \mathrm{q} 11.2$ \\
\hline GGGGCAGTGA & Hs.38512 & KIAA1285 protein (KIAA1285) & 1 & 4.08 & $7 \mathrm{q} 36.1$ \\
\hline GGGGCGGGGT & Hs.474970 & Zinc finger CCCH-type containing 7B (RoXaN) & 1 & 4.08 & $22 q 13.2$ \\
\hline GGTCGGAAAA & BU536065 & EST & 1 & 4.08 & \\
\hline GATTGATGTC & Hs.491912 & $\begin{array}{l}\text { COP9 constitutive photomorphogenic homolog subunit } 5 \text { (Arabidopsis) } \\
\text { (COPS5) }\end{array}$ & 1 & 4.08 & $8 \mathrm{q} 13.2$ \\
\hline GCAACAAATT & Hs.479602 & $\begin{array}{l}\text { Amyloid beta (A4) precursor protein-binding, family B, member } 2 \\
\text { (Fe65-like) (APBB2) }\end{array}$ & 1 & 4.08 & $4 \mathrm{p} 14$ \\
\hline ATGGCAGAAG & Hs. 552746 & Hypothetical protein LOC284889 (LOC284889) & 1 & 4.08 & $22 q 11.23$ \\
\hline TTGGGTTCCA & H53496 & EST & 1 & 4.08 & \\
\hline TCTGCAAAAA & Hs. 405880 & Mitochondrial ribosomal protein S21 (MRPS21) & 1 & 4.08 & 1 \\
\hline GCCTACCCGA & Hs.23582 & Tumor-associated calcium signal transducer 2 (TACSTD2) & 1 & 4.08 & $1 \mathrm{p} 32-\mathrm{p} 31$ \\
\hline GTGGCGGGTG & Hs.288520 & Hypothetical gene FLJ00060 (FLJ00060) & 1 & 4.08 & $19 q 13.42$ \\
\hline ACCCACAGTG & Hs.67896 & Opioid growth factor receptor (OGFR) & 1 & 4.08 & $20 \mathrm{q} 13.3$ \\
\hline TGCTGCCTCA & Hs.30792 & Hook homolog 2 (Drosophila) (HOOK2) & 1 & 4.08 & $19 \mathrm{p} 13.13$ \\
\hline TAAGATTTCA & Hs.373763 & Heterogeneous nuclear ribonucleoprotein R (HNRPR) & 1 & 4.08 & $1 \mathrm{p} 36.12$ \\
\hline TACATTTCAA & Hs.368542 & Proprotein convertase subtilisin/kexin type 5 (PCSK5) & 1 & 4.08 & $9 q 21.3$ \\
\hline TATGTTTCAG & Hs.61812 & Protein tyrosine phosphatase, non-receptor type 12 (PTPN12) & 1 & 4.08 & $7 q 11.23$ \\
\hline ATCCGCCTGC & Hs. 514557 & cDNA FLJ41626 fis, clone DFNES1000107 & 1 & 4.08 & 17 \\
\hline GATTTAAATC & Hs.501857 & RAB6 interacting protein 1 (RAB6IP1) & 1 & 4.08 & $11 \mathrm{p} 15.4$ \\
\hline CGAGACTGGT & Hs.75438 & Quinoid dihydropteridine reductase (QDPR) & 1 & 4.08 & $4 \mathrm{p} 15.31$ \\
\hline CGTGAGCCAC & Hs.462303 & Tripartite motif-containing 16 (TRIM16) & 1 & 4.08 & $17 \mathrm{p} 11.2$ \\
\hline GCAGCTAATT & Hs.202011 & GK001 protein (GKD01) & 1 & 4.08 & $17 \mathrm{q} 23.3$ \\
\hline AATAAAGCAT & BM468964 & EST & 1 & 4.08 & \\
\hline GCTTAATGTG & Hs.334885 & GTP binding protein 3 (mitochondrial) (GTPBP3) & 1 & 4.08 & 19p13.11 \\
\hline ACTAACACCT & CF456631 & EST & 1 & 4.08 & \\
\hline CATCCAAGGC & Hs.462392 & Hypothetical protein FLJ20308 (FLJ20308) & 1 & 4.08 & $17 \mathrm{p} 11.2$ \\
\hline TGGGGAAAAG & Hs. 445652 & Transformer-2 alpha (TRA2A) & 1 & 4.08 & $7 \mathrm{p} 15.3$ \\
\hline AGCACCTCAG & BF378578 & EST & 1 & 4.08 & \\
\hline GAATAATCTT & Hs. 480815 & Short coiled-coil protein (SCOC) & 1 & 4.08 & $4 \mathrm{q} 31.1$ \\
\hline AGCCACCGTG & Hs. 162233 & Chromodomain helicase DNA binding protein 4 (CHD4) & 1 & 4.08 & $12 \mathrm{p} 13$ \\
\hline GATACTTGAC & Hs.473082 & Zinc finger protein 64 homolog (mouse) (ZFP64) & 1 & 4.08 & $20 \mathrm{q} 13.2$ \\
\hline ATCATTCCCT & Hs. 531788 & Dpy-30-like protein (LOC84661) & 1 & 4.08 & $2 \mathrm{p} 22.3$ \\
\hline TTGCCTGTAT & Hs.546305 & $\begin{array}{l}\text { Transcription elongation factor B (SIII), polypeptide } 1 \text { ( } 15 \mathrm{kDa} \text {, elongin C) } \\
\text { (TCEB1) }\end{array}$ & 1 & 4.08 & $8 \mathrm{q} 21.11$ \\
\hline TCCAGAATAC & Hs.463607 & Family with sequence similarity 33 , member A (FAM33A) & 1 & 4.08 & $17 \mathrm{q} 23.2$ \\
\hline TTGGTTTTGT & Hs.131434 & Coiled-coil-helix-coiled-coil-helix domain containing 3 (CHCHD3) & 1 & 4.08 & $7 q 32.3-q 33$ \\
\hline CTGACGGGTA & Hs.63795 & Hypothetical protein DKFZp434L0117 (DKFZP434L0117) & 1 & 4.08 & $1 \mathrm{p} 36.11$ \\
\hline
\end{tabular}


Table III supplementary. Continuted.

\begin{tabular}{|c|c|c|c|c|c|}
\hline TAG & UniGene & Description (locus name) & HB4a & C5 5.2 & $\begin{array}{l}\text { Chromosome } \\
\text { region }\end{array}$ \\
\hline CAAGCCATCC & BF938487 & EST & 1 & 4.08 & \\
\hline CACAACCTGG & BE170306 & EST & 1 & 4.08 & \\
\hline GTGGCGGGCA & Hs.369632 & Hypothetical protein FLJ38482 (FLJ384820 & 1 & 4.08 & $4 q 32.3$ \\
\hline GTGTTCCTGG & Hs. 162877 & Protein kinase $\mathrm{C}$ and casein kinase substrate in neurons 2 (PACSIN2) & 1 & 4.08 & $22 q 13.2-13.33$ \\
\hline CACTGCCTGT & Hs.325309 & Chromosome 9 open reading frame 54 (C9orf54) & 1 & 4.08 & $9 \mathrm{q} 34.11$ \\
\hline АСАССТСТАА & Hs. 149185 & CNDP dipeptidase 2 (metallopeptidase M20 family) (CNDP2) & 1 & 4.08 & $18 \mathrm{q} 22.3$ \\
\hline ACAGTGTTAA & Hs.385913 & $\begin{array}{l}\text { Acidic (leucine-rich) nuclear phosphoprotein } 32 \text { family, member E } \\
\text { (ANP32E) }\end{array}$ & 1 & 4.08 & $1 \mathrm{q} 21.2$ \\
\hline ACATTCCAAG & Hs. 297324 & $\begin{array}{l}\text { Tissue inhibitor of metalloproteinase } 3 \text { (Sorsby fundus dystrophy, } \\
\text { pseudoinflammatory) (TIMP3) }\end{array}$ & 1 & 4.08 & $22 q 12.1-q 13.2$ \\
\hline CTTGACACAC & H47931 & EST & 1 & 4.08 & \\
\hline TGGAACTGTA & Hs.303727 & Chromosome 10 open reading frame 4 (C10orf4) & 1 & 4.08 & $10 q 23.33$ \\
\hline TAAATATAAA & Hs.416998 & Mitochondrial ribosomal protein L18 (MRPL18) & 1 & 4.08 & $6 \mathrm{q} 25.3$ \\
\hline AGAAAGGGAG & Hs.436181 & Homeo box B7 (HOXB7) & 1 & 4.08 & $17 \mathrm{q} 21.3$ \\
\hline GGCAGAGGTT & H82959 & EST & 1 & 4.08 & \\
\hline TGTCTTTATA & Hs. 551978 & cDNA FLJ25632 fis, clone STM03991 & 1 & 4.08 & 18 \\
\hline ATATGTATAT & Hs. 502328 & CD44 antigen (homing function and Indian blood group system) (CD44) & 1 & 4.08 & $11 \mathrm{p} 13$ \\
\hline TCACAACAAA & AW875846 & EST & 1 & 4.08 & \\
\hline
\end{tabular}

